\title{
Contrasting Characteristics between the Northward and Eastward Propagation of the Intraseasonal Oscillation during the Boreal Summer
}

\author{
Huang-Hsiung Hsu, Chun-Hsiung Weng, and Cheng-Han Wu \\ Department of Atmospheric Sciences, National Taiwan University, Taipei, Taiwan
}

(Manuscript received 29 October 2002, in final form 9 April 2003)

\begin{abstract}
This study investigates the structural and evolutionary characteristics of the eastward- and northward-propagating intraseasonal oscillation (ISO) in the Indian Ocean and western Pacific during the boreal summer. Along the equator, the near-surface moisture convergence located to the east of the deep convection region appears to result in the eastward propagation of the ISO, consistent with the frictional wave-CISK (conditional instability of the second kind) mechanism proposed in previous studies. The eastward propagation is characterized by sequentially downstream development of deep convection occuring mainly in certain regions such as $60^{\circ}, 95^{\circ}$, $120^{\circ}$, and $145^{\circ} \mathrm{E}$, and the date line.

The northward propagation of deep convection can be attributed to the low-level moisture convergence located to the north. This convergence is a deep structure extending from the surface to the middle troposphere. Nearsurface convergence appears only after the systems approach the landmass in the north. It is suggested that both the deep convergence in the lower free atmosphere and in the boundary layer contribute to the northward propagation. The lifting effect of the sloping terrain and the stronger surface frictional effect over the land in South Asia contribute to the near-surface convergence north of the deep convection. The northward propagation occurs sequentially from west to east in the following order: the Arabian Sea, the Bay of Bengal, and the South China Sea. A mechanism is proposed to explain this downstream occurrence of northward propagation.

It was also found that surface sensible heating might contribute to the northward propagation, especially in the Arabian Sea, by making the lower troposphere less stable. Latent heat flux is released to the atmosphere in the region located to the southwest of the deep convection and does not directly contribute to the destablization in the lower troposphere ahead of the deep convection. In contrast, during the eastward propagation the surface heating does not seem to precondition the lower troposphere to the east of the deep convection. Frictional convergence is seemingly the dominant factor in the eastward propagation.
\end{abstract}

\section{Introduction}

The intraseasonal oscillation (hereafter referred to as ISO) has a significant effect on the subseasonal atmospheric variability in the Tropics. One of the most prominent features related to the ISO is the eastward propagation along the equator. This is evident primarily from the Indian Ocean to the date line during the boreal winter. Since the discovery of ISOs such as the MaddenJulian oscillation by Madden and Julian (1971, 1972), many mechanisms based largely on equatorial wave dynamics have been proposed to explain this phenomenon. Lau and Peng (1987) proposed the mobile Kelvin waveCISK (conditional instability of the second kind) mechanism emphasizing the interaction between the positiveonly heating and the unstable Kelvin waves. This mechanism suppresses the Rossby wave and leads to the eastward propagation.

Corresponding author address: Dr. Huang-Hsiung Hsu, Dept. of Atmospheric Sciences, National Taiwan University, No. 1, Section 4, Roosevelt Rd., Taipei 106, Taiwan.

E-mail: hsu@atmos1.as.ntu.edu.tw
Hayashi and Sumi (1986) and Hendon (1988) suggested that the coupled Kelvin-Rossby mode is the dominant feature. Wang and Rui (1990a) further proposed, based on a theoretical study using an equatorial $\beta$-plane model, that the frictional moisture convergence in the boundary layer is essential for the growth of the unstable Kelvin-Rossby wave mode. Within this coupled mode, the Kelvin mode is unstable while the Rossby mode is damped. However, the coupling between the two modes results in an unstable coupled mode and slows down the eastward propagation. It also provides a selection mechanism that favors the growth of planetary-scale disturbances. This frictional wave-CISK was confirmed by both numerical (e.g., Salby et al. 1994; Seager and Zebiak 1994) and empirical studies (e.g., Hendon and Salby 1994; Jones and Weare 1996; Maloney and Hartmann 1998). The moisture convergence located to the east of the deep convection moistens the boundary layer and creates a potentially unstable condition. Conversely, the Rossby mode located to the west of the active convection is associated with a nearsurface divergence anomaly. The coupled Kelvin-Rossby wave packet therefore propagates eastward. 
Recent studies (e.g., Hendon and Glick 1997; Flatau et al. 1997; Woolnough et al. 2000) have found that the deep convection passage associated with the ISO results in a significant drop in sea surface temperature, owing to the increased cloudiness and the enhanced evaporation associated with a strong westerly anomaly. This result implies that an active ocean-atmospheric interaction is embedded in the ISO, although the ocean tends to play a more passive role in response to the atmospheric forcing.

In addition to the eastward propagation, the ISO also propagates northward in South Asia during the boreal summer. This phenomenon has been reported in many case studies (e.g., Yasunari 1979, 1981; Sikka and Gadgil 1980; Krishnamurti and Subrahmanyam 1982; Murakami and Nakazawa 1985). This northward-propagating feature appears repeatedly from year to year and is closely associated with the active and break phases of the South Asian monsoon (e.g., Sikka and Gadgil 1980; Chen et al. 1988; Wu et al. 1999). Statistics identifying the northward propagation can be found in Lau and Chan (1986), Knutson and Weickmann (1987), and Wang and Rui (1990b).

In contrast to the eastward propagation, the mechanisms responsible for the northward propagation are not as well understood. Webster (1983) suggested, based on simulated results using an idealized two-dimensional coupled ocean-atmosphere model, that the ground hydrology feedback creates a meridional heating gradient in such a manner that the maximum heating is always located to the north of the maximum upward motion. This phase difference results in northward propagation, although the simulated periodicity is shorter than the observed. This result was further confirmed by Srinivasan et al. (1993) using a revised model to lengthen the simulated periodicity. A different view was provided by Goswami and Shukla (1984). They found that in a zonally symmetrical model the convective dynamical feedback inherent in the Tropics could result in an oscillation between convectively stable and unstable regimes and therefore explain the oscillation in the Hadley-type circulation prevailing in South Asia and the Indian Ocean during the boreal summer. This model also simulated a wave perturbation in the lower troposphere moving from the Southern Hemisphere to $20^{\circ} \mathrm{N}$ and then becoming stationary. This wave was not simulated in a dry land simulation and was thus suggested to be maintained by the latent heating due to land surface evaporation. Conversely, Ferranti et al. (1999) concluded, based on general circulation model simulations, that northward propagation simulation does not require including the interactive surface hydrological processes.

In an equatorial $\beta$-plane model, tropical heating forces a Kelvin-Rossby wave packet accompanied by horseshoe-shaped convection. This forms at the eastern edge of the Rossby wave and tilts northwestward in the low latitudes of the Northern Hemisphere. Wang and Xie (1997) suggested that the northward propagation is ob- served as the wave packet moves eastward. Lawrence and Webster (2002) found that most of the northward propagation was associated with the eastward propagation along the equator. Wang and Xie (1996) and Maloney and Hartmann (1998) suggested that the northward propagation could be attributed to the northwestward emanation of an equatorial Rossby wave, which is forced by tropical heating moving eastward along the equator.

Recent studies (e.g., Kemball-Cook and Wang 2001; Lawrence and Webster 2002) have found the existence of near-surface convergence to the north of the deep convection. This phase difference is suggested to result in the northward propagation. Kemball-Cook and Wang (2001) further suggested that underlying surface heating might also contribute to this propagation. This mechanism, although similar, is different from the frictional convergence for the eastward propagation, because the latter is caused by the Kelvin waves affected by the friction. It is not clear how the near-surface convergence north of the deep convection is induced by equatorial waves, although a frictional effect on the Rossby waves has been suggested (e.g., Hendon and Salby 1994; Hsu and Weng 2001; Lawrence and Webster 2002).

Krishnan and Venkatesan (1997) provided a different perspective based on mobile wave-CISK. A deep convection, which appears initially near the equator, is embedded in a reversed Hadley circulation with upward motion over the Asian continent and subsidence in the Southern Hemisphere. The secondary circulation associated with this convection enhances the southerly winds located to the south of the convection, while the southerly flow located to the north is weakened. The result is a shift in the maximum low-level convergence to the north of the convection and the subsequent northward propagation of this convection.

The eastward propagation occurs mainly near the Tropics and over the ocean, while the northward-propagating mode moves from south to north and from ocean to land. The former occurs in both summer and winter, while the latter occurs mainly in the boreal summer. The different land-sea distribution and the different underlying surface properties are likely to result in distinctively different characteristics in the eastward- and northward-propagating ISO. Consequently, the mechanisms for both propagation regimes were proposed based on different processes. Most of the proposed mechanisms for the eastward propagation are based on the equatorial wave dynamics. Some of them even take into account the ocean-atmosphere interaction. In contrast, the atmosphere-land interaction was proposed as a mechanism to explain the northward propagation. Despite these differences, most of the proposed mechanisms for both the eastward and northward propagation stress the importance of the energy exchange between the atmosphere and the underlying surfaces through boundary layer processes.

In the boreal summer, the ISO propagates both north- 
ward and eastward in the Indian Ocean and South Asia (Wang and Rui 1990b). However, their respective evolutions, structures, and mechanisms are distinctly different. The discussion in the preceding paragraph reveals that the mechanisms proposed for the eastward propagation have a greater degree of consensus, while those for the northward propagation differ significantly. A detailed comparison between the characteristics associated with both propagations could reveal valuable information on how the circulation-convection interaction, which is the essence of the ISO, operates differently over different types of underlying surfaces. Based on the above motivation, this empirical study investigated both propagations, documented and contrasted their different characteristics, and proposes a mechanism to explain the northward propagation.

The arrangement of this paper is as follows. Section 2 describes the dataset and analysis procedures. Section 3 discusses the basic characteristics of the convection and circulation associated with the ISO. The evolution of a major ISO mode is shown in section 4, and the mechanism responsible for propagation is presented in section 5 along with discussions and conclusions.

\section{Data and analysis procedure}

The data used in this study include 1) the European Centre for Medium-Range Weather Forecasts (ECMWF) Re-Analysis (ERA; Gibson et al. 1997), 2) the optimally interpolated sea surface temperature (SST) produced by the National Centers for Environmental Prediction (Reynolds and Smith 1994), and 3) the interpolated outgoing longwave radiation (OLR; Liebmann and Smith 1996). The ERA and OLR data cover 15 summers (defined as May-August) from 1979 to 1993, while the SST data cover only 12 summers from 1982 to 1993 . The ERA and OLR resolution is $2.5^{\circ} \times$ $2.5^{\circ}$, while the SST is on a $1^{\circ} \times 1^{\circ}$ grid. The SST data, originally available weekly, were interpolated linearly into the daily data. This procedure did not produce higher-frequency signals. It did, however, create a dataset that is convenient for the bandpass-filtering procedure described below.

To isolate the intraseasonal signals, all data were filtered through a 30-60-day bandpass Butterworth filter (Hamming 1989). Zonal means were then removed to emphasize the eddy components of the circulation. To show the large-scale structure clearly, all data except the SST were spatially smoothed using a T24 spectral smoothing technique proposed by Sardeshmukh and Hoskins (1984). One might suspect that the spatial smoothing could smear out the detailed structure associated with the ISO in the monsoon region. The statistics presented below were double-checked by comparing them to those derived from the nonsmoothed fields. It was found that, although some of the detailed structure might be smoothed out, the smoothing procedure did not remove features that would lead to dif- ferent conclusions. Smoothing also helped isolate the most concerned large-scale features embedded in the ISO.

Regression analysis was applied in this study to delineate the temporal evolution and the spatial structure of the ISO. Statistical significance tests were applied to all regresion maps. The $t$ score of each regression coefficient was computed. The null hypothesis of no relationship was rejected when the computed $t$ score was larger than the $t$ value at $95 \%$ in the Student's $t$ distribution. Only those results rejecting the null hypothesis are plotted in the following figures.

\section{Characteristics of convection and circulation}

The atmosphere exhibits significant ISO variability in the Indian Ocean and over South Asia. Figure 1a presents the total variance of the OLR that was not filtered in time and smoothed in space. The largest variance appears in northern India, the Bay of Bengal, the eastern Arabian Sea, the equatorial Indian Ocean, and the South China Sea. To identify the major ISO activity regions, the ratio for the bandpass-filtered OLR variance to the total variance is shown in Fig. 1b. The filtered OLR used in this calculation was not smoothed in space. The Arabian Sea, the Bay of Bengal, and the eastern Indian Ocean are the regions where the ratio is significantly larger than $12 \%$. A blank area in the central southern Indian Ocean between the equator and $20^{\circ} \mathrm{S}$ indicates the location of the weakest ISO signals. The ISO appears to be most active in the oceanic regions where the total variance is large.

The deep convection exhibits a complex propagation route distribution as revealed by the arrows shown in Fig. 1c, which were computed based on the simultaneous and 5-day-lagged one-point correlation maps for every grid point. The arrows are plotted to indicate the distance and the direction the OLR anomaly moves from each grid point to the point where the correlation coefficient is largest 5 days later. The deep convection in the equatorial western and eastern Indian Oceans exhibits different characteristics. The OLR anomaly tends to propagate eastward along the equator in the equatorial western Indian Ocean, while in the eastern Indian Ocean it propagates both northward and southward away from the equator. This implies a weaker eastward propagation in the eastern Indian Ocean, a characteristic distinctively different from its counterpart in the boreal winter. Northward and northeastward propagation are also evident in the Arabian Sea. In the southwestern Indian Ocean, south of $5^{\circ} \mathrm{S}$ where the ISO signal is weak, there are no clear propagation signals. A comparison with Fig. 1a indicates that northward propagation occurs mostly in the regions where the ISO variance ratios are large. If the northward propagation in the Indian Ocean were due to the horseshoe-shaped convection passage associated with the Kelvin-Rossby wave packet, as proposed by Wang and Xie (1997), one should see vectors pointing 
(a) OLR

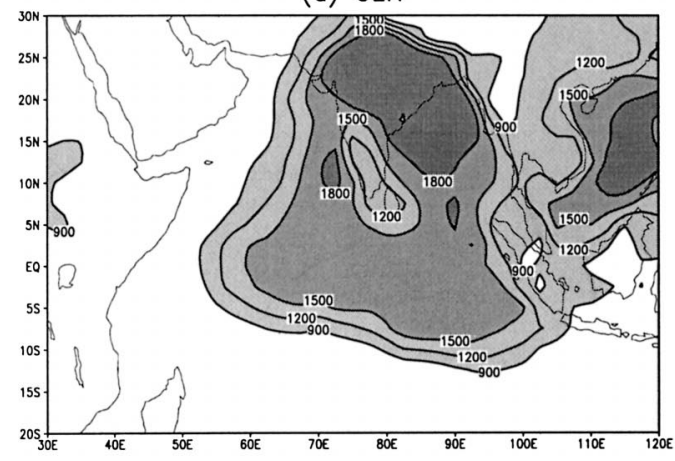

(c) OLR

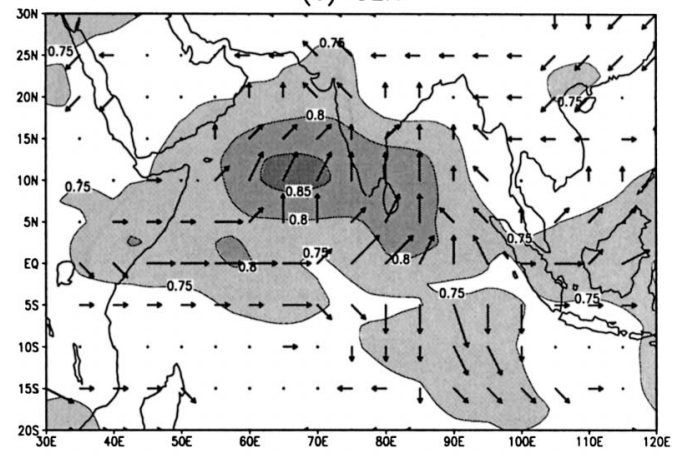

(b) OLR

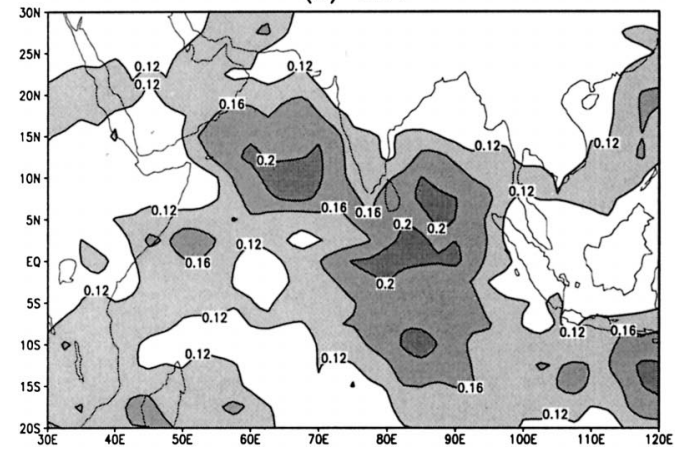

(d) VOR850

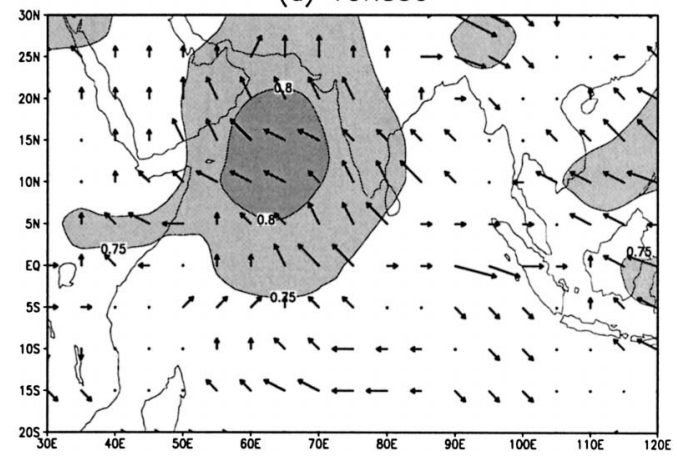

FIG. 1. (a) Total variance of the OLR that was not filtered in time or smoothed in space; (b) ratio of the 30-60day variance to the total variance for OLR. Contour intervals are $300 \mathrm{~W}^{2} \mathrm{~m}^{-2}$ and 0.04 in (a) and (b), respectively. Only values larger than $900 \mathrm{~W}^{2} \mathrm{~m}^{-2}$ and 0.12 are plotted and shaded in (a) and (b), respectively. Tendencies of the (c) OLR and (d) 850 -hPa vorticity anomaly propagation derived from the 5-day lagged correlation are shown as arrows. Arrows indicate the direction and distance for an anomaly propagating from the base point to the end point in 5 days, while the contours indicate the 5-day lagged correlation coefficients. Correlation coefficients larger than 0.75 are shaded in (c) and (d), and the contour interval is 0.05 .

toward the east instead of the north as shown in Fig. 1c. This result suggests that the northward propagation does exist and is not an illusion one sees at the same longitude as the wave packet passes. In addition, our results agree with previous empirical studies (e.g., Sikka and Gadgil 1980) that the northward propagation of the deep convection originates near the equator and over the ocean.

The movement of the corresponding circulation in the lower troposphere can be represented by the vectors of the 850-hPa vorticity field shown in Fig. 1d. The most favorable propagation direction is northwestward and mainly occurs in the Arabian Sea and the Bay of Bengal where the 5-day-lagged correlation is at its maximum. The region of maximum lag correlation for the OLR is located to the east of the region for the $850-\mathrm{hPa}$ vorticity. This phase relationship is consistent with the tropical heating-circulation relationship revealed in the theoretical study by Gill (1980).

In order to extract the most active mode that couples the tropical convection and large-scale circulation during the boreal summer, the singular value decomposition
(SVD; Bretherton et al. 1992) was applied to the covariance matrix of the normalized OLR and $850-\mathrm{hPa}$ streamfunction. Figure 2 shows the first and second singular vectors, which explain $38.7 \%$ and $27.3 \%$ of the squared covariance, respectively. The percentages of the explained variances by these vectors can also be calculated for the individual field (Wallace et al. 1992). The two OLR vectors shown in Fig. 2 explain $16 \%$ and $15 \%$ of the OLR variance, and the two streamfunction vectors shown in Fig. 2 explain 18\% and 14\% of the streamfunction variance. These two sets of vectors are also the first two empirical orthogonal functions of the respective field (not shown). The correlation between the expansion coefficients of the OLR and the streamfunction are 0.94 and 0.89 for the first and second singular vectors, respectively.

The first singular vector exhibits a hemispheric-scale OLR teleconnection pattern. For example, when the OLR anomalies in South Asia and the western Pacific are negative, their counterparts in the eastern Pacific, the Atlantic, and over Africa are positive. The corresponding $850-\mathrm{hPa}$ streamfunction pattern consists of a 


\section{(a)SVD1}

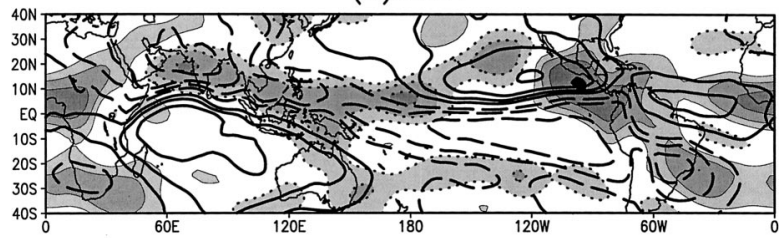

(b)SVD2

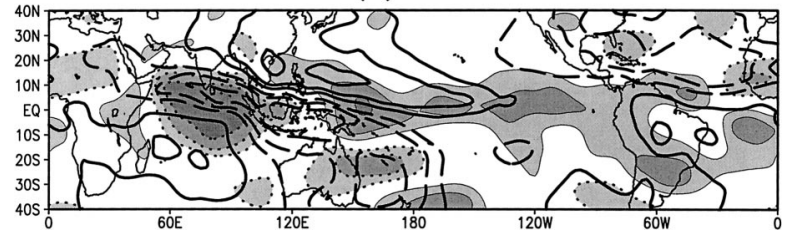

FIG. 2. (a) First and (b) second singular vectors of OLR and 850 $\mathrm{hPa}$ streamfunction anomalies presented in terms of correlation. Correlations for OLR larger than 0.2 and less than -0.2 are shaded and outlined by thin solid and dotted lines, respectively. Positive and negative correlations for the streamfunction are shown as thick solid and dashed lines, respectively. The shading and the contour interval is 0.2 .

north-south cyclonic dipole over South Asia and the Indian Ocean and a north-south anticyclonic dipole over the eastern Pacific. Both dipoles are located to the west of the corresponding OLR anomalies. The tight gradient embedded in these two dipoles indicates a negatively correlated variation between the tropical $850-\mathrm{hPa}$ zonal wind in the Indian Ocean and the equatorial eastern Pacific. In the second singular vector, the negative OLR anomaly is located mainly in the tropical Indian Ocean while the positive anomaly spreads from the western Pacific to the eastern Pacific along the equator. The corresponding $850-\mathrm{hPa}$ circulation, which tends to be located to the west of the OLR anomalies, is a cyclonic dipole in the Indian Ocean and an anticyclonic dipole in the western Pacific. These circulation characteristics are consistent with the results from previous studies (e.g., Maloney and Hartmann 1998).

An inspection of the corresponding expansion coefficient (not shown here) reveals that both vectors often oscillate for several cycles, and that the second vector tends to lead the first vector by about a quarter of the cycle. This result indicates that the first and second singular vectors are two orthogonal components of an oscillating mode that propagates in space in certain regions. The leading phase of the second vector relative to the first vector suggests a northward propagation in the Indian Ocean and over South Asia.

\section{Contrasting characteristics of the eastward and northward propagations}

This section examines the evolution and characteristics of the coupled mode represented by the first and second singular vectors. Because of the strong corre- lation between the first and second vectors, only the lagged regression maps between the first expansion coefficient and various variables at different time lags are shown. The regression coefficients shown in the following figures are statistically significant at the 0.05 significance level based on the null hypothesis with no correlation. Similar results could be obtained based on the second expansion coefficient. Because this study is concerned mainly with the ISO propagation in Asia, the Indian Ocean, and the western Pacific, the following figures are plotted in a domain from $20^{\circ} \mathrm{S}$ to $40^{\circ} \mathrm{N}$ and from $40^{\circ} \mathrm{E}$ to $160^{\circ} \mathrm{W}$. The following discussion will interpret the negative OLR values as enhanced convection and focus on the corresponding fluctuations when the convection in the Indian Ocean and over South Asia is in its active phase.

\section{a. Convection and circulation}

Figure 3 presents the lagged regression between the first OLR expansion coefficient and the OLR and the $850-\mathrm{hPa}$ streamfunction from day -20 to day 5 . The patterns tend to repeat themselves after day 5 in opposite signs. This can be seen clearly by comparing Figs. 3a,b with Figs. 3e,f. The evolution after day 5 can therefore be inferred from day -20 onward by reversing the signs. One can clearly see both eastward and northward propagation in the series of plots shown in Fig. 3. Detailed features are described as follows.

The eastward propagation occurs along two latitudinal bands, that is, near the equator and around $10^{\circ}-$ $20^{\circ} \mathrm{N}$. The former is described here and the latter will be discussed later. At day -20 , two active convection regions centered at $60^{\circ}$ and $90^{\circ} \mathrm{E}$ begin developing in the equatorial Indian Ocean while the inactive convection in South Asia and the western Pacific is at its peak. The eastern center develops rapidly from day -20 to day -10 while remaining stationary. A narrow band of active convection along the equator begins extending eastward into the Maritime Continent at day -10 . It develops into a much wider band at day -5 and continues expanding and moving eastward along the equator to the date line by day 5 . This eastward propagation exhibits characteristics similar to those of the eastwardpropagating Madden-Julian oscillation.

During the period when the convection develops and propagates eastward in the Maritime Continent and the equatorial Western Pacific, two active convection centers in the Indian Ocean propagate northward. When the convection is well developed at day -15 , the western center begins propagating northeastward from the equatorial western Indian Ocean to northwestern India. The eastern center moves northward from the equatorial eastern Indian Ocean to the Bay of Bengal from day -10 to day 5, lagging its counterpart in the Arabian Sea by about 5 days. Five days later at day -5 , northward propagation of the active convection region occurs in the South China Sea. Similar northward propagation 
(a)lag reg of PSI850, OLR(shading) lag day $=-20$

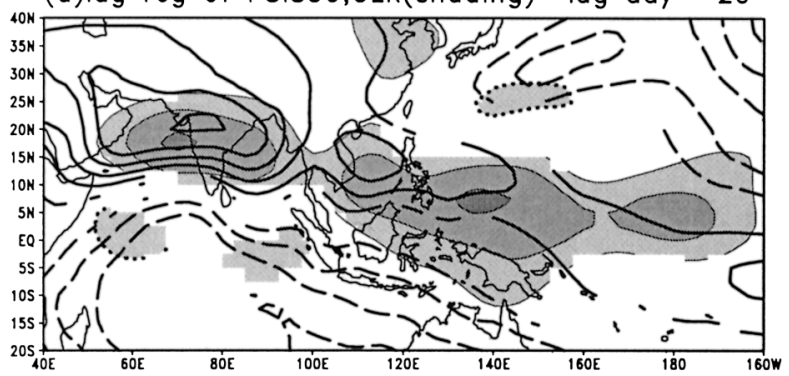

(b) $\operatorname{lag}$ day $=-15$

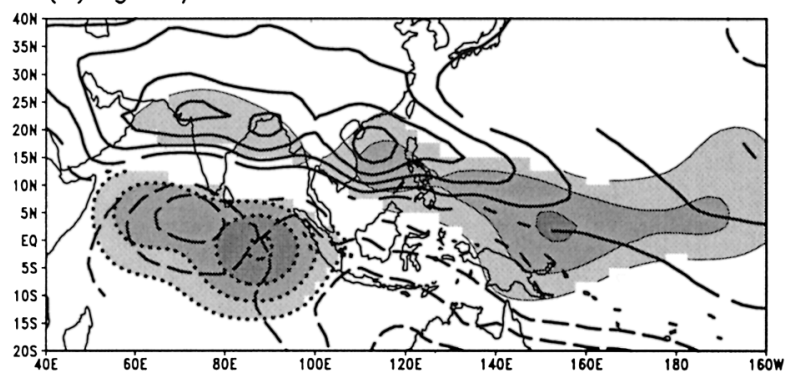

(c) lag day $=-10$

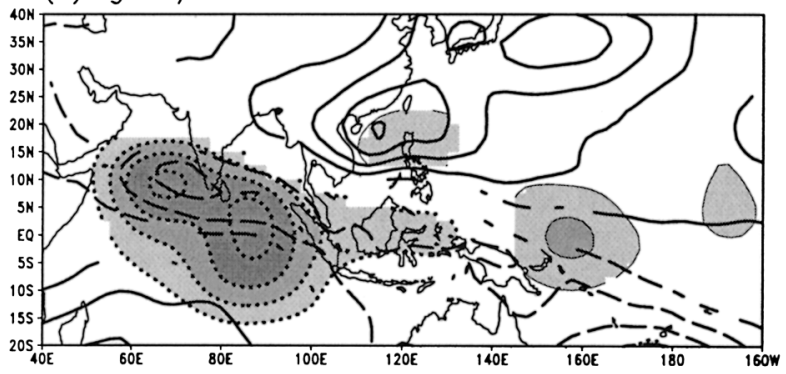

(d) $\operatorname{lag}$ day $=-5$

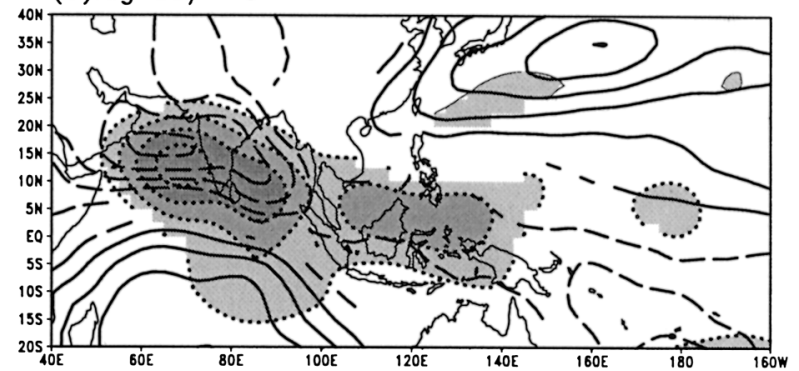

(e) $\operatorname{lag}$ day $=0$

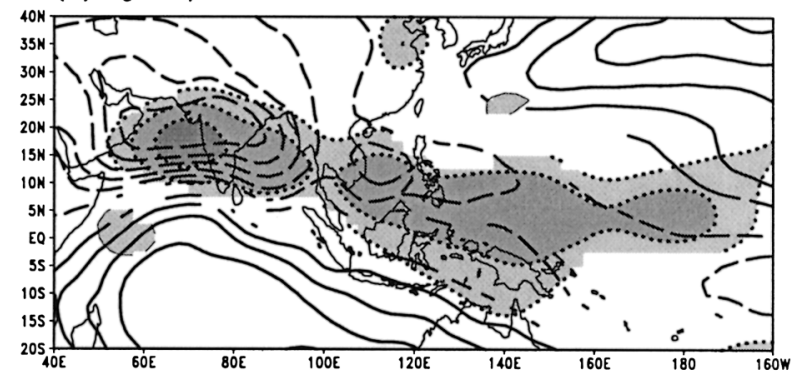

(f) lag day $=5$

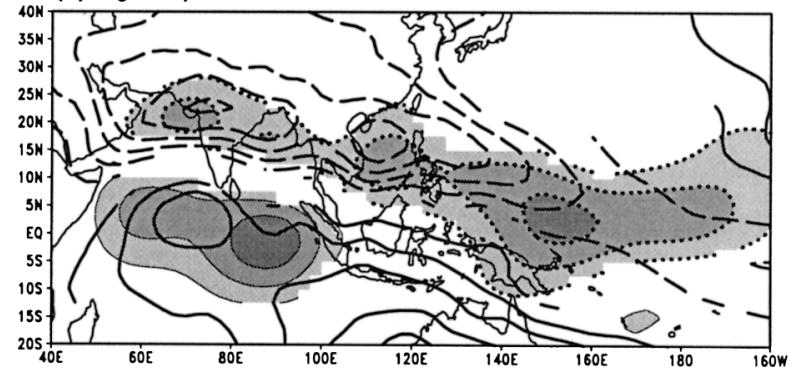

FIG. 3. Lagged regression coefficients between the expansion coefficient of the first OLR vector and the OLR (shaded) and 850-hPa streamfunction (contoured) anomalies at (a) day -20 , (b) day -15 , (c) day -10 , (d) day -5 , (e) day 0, and (f) day 5. OLR anomalies larger than $2 \mathrm{~W} \mathrm{~m}^{-2}$ and less than $-2 \mathrm{~W} \mathrm{~m}^{-2}$ are outlined by thin solid and dotted lines, respectively. Streamfunction anomalies larger than $0.2 \times 10^{6} \mathrm{~m}^{2} \mathrm{~s}^{-1}$ and less than $-0.2 \times 10^{6} \mathrm{~m}^{2} \mathrm{~s}^{-1}$ are plotted in solid and dashed lines, respectively. Contour intervals are $2 \mathrm{~W} \mathrm{~m} \mathrm{~m}^{-2}$ and $0.2 \times 10^{6} \mathrm{~m}^{2} \mathrm{~s}^{-1}$ for the OLR and streamfunction, respectively. Regression coefficients have been multiplied by one standard deviation of the expansion coefficient and only those that are significant at the 0.05 level are plotted.

in the South China Sea was documented by Chen et al. (2000). Wang and Rui (1990b) reported two types of northward propagation in the region: independent northward propagation and northward propagation associated with eastward propagation in the equator. The northward propagation reported here corresponds to the second type. The independent northward propagation will not be discussed here.

According to the above results, the first and second singular vectors together capture most of propagating features in South and Southeast Asia shown in Fig. 1c, except the southward-propagating features in the southeastern Indian Ocean. This confirms the appropriateness of using the first two singular vectors to represent the major characteristics of the ISO in this region.

The 850-hPa streamfunction, also shown in Fig. 3, exhibits a close relationship with the OLR. An anom- alous cyclonic circulation associated with the active convection in the western Indian Ocean propagates northward from the equator to about $25^{\circ} \mathrm{N}$ from day -15 to day 5. Another pair of anomalous cyclonic circulation centers appears in the South China Sea and the western Pacific at day 0 and expands eastward together with the eastward-expanding active convection region at the equator. These cyclonic circulations bear characteristics similar to the Rossby wave forced by tropical heating (Gill 1980).

The results shown in Fig. 3 reveal that the northward propagation occurs earliest in the Arabian Sea and over India, then in the Bay of Bengal, and finally in the South China Sea. This sequence could be mistaken as an eastward-propagating feature along the $10^{\circ}-20^{\circ} \mathrm{N}$ latitudinal band if plotted as a Hovmöller diagram. In fact, this phenomenon consists of three separate convection 
(a)lag reg of $925 \mathrm{hPa}$ DIVVQ,UVQ lag day $=-20$

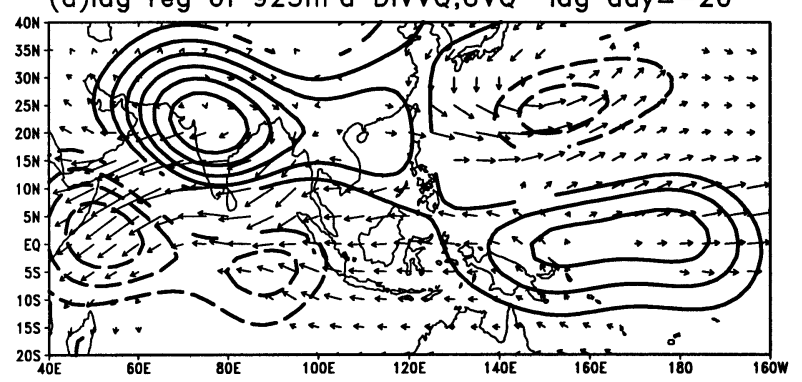

(b) lag day $=-15$

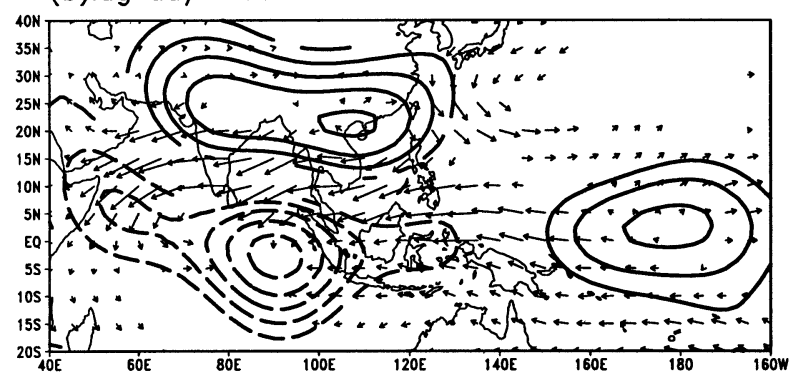

(c) $\operatorname{lag}$ day $=-10$

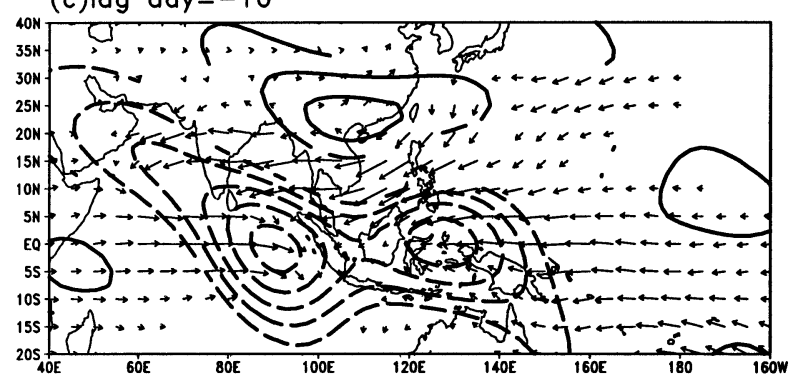

(d) lag day $=-5$

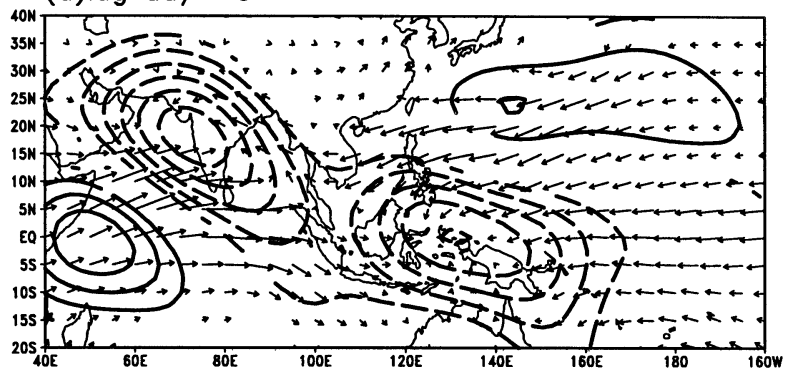

(e) $\operatorname{lag}$ day $=0$

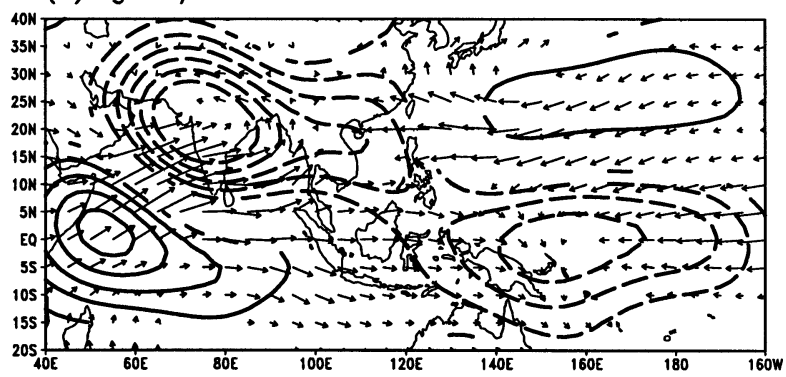

(f) lag day=5

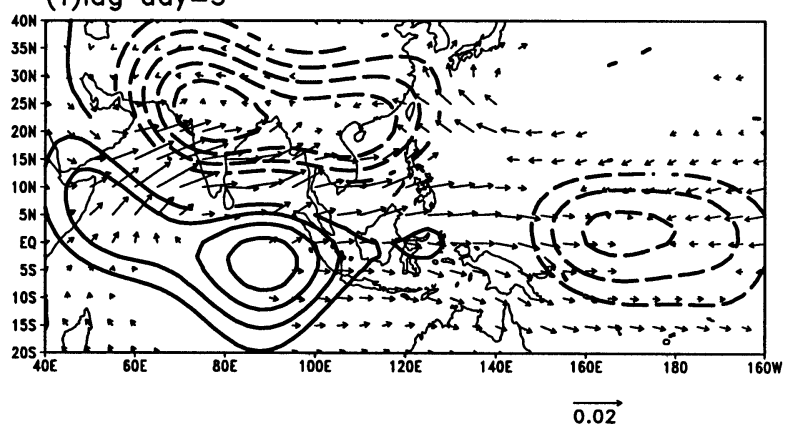

FIG. 4. Lagged regression coefficients between the expansion coefficient of the first OLR vector and the moisture flux $(\mathbf{V} Q)$ and corresponding divergence $\boldsymbol{\nabla} \cdot(\mathbf{V} Q)$ anomalies at $925 \mathrm{hPa}$ at (a) day -20 , (b) day -15 , (c) day -10 , (d) day -5 , (e) day 0 , and (f) day 5. The divergence anomalies larger than $5 \times 10^{-10}$ and less than $-5 \times 10^{-10} \mathrm{~g} \mathrm{~kg}^{-1} \mathrm{~m} \mathrm{~s}^{-2}$ are plotted in solid and dashed lines, respectively, and the contour interval is $5 \times 10^{-10} \mathrm{~g} \mathrm{~kg}^{-1} \mathrm{~m} \mathrm{~s}^{-2}$. The moisture flux is presented as vectors. The unit vector shown in the lower-right corner corresponds to $0.02 \mathrm{~g} \mathrm{~kg}^{-1} \mathrm{~m} \mathrm{~s}^{-1}$. The regression coefficients have been multiplied by one standard deviation of the expansion coefficient and only those that are significant at the 0.05 level are plotted.

anomalies that propagate northward. These anomalies become stationary soon after they reach the landmass in the north. The sequential northward propagation results in the increasing zonal scale of the circulation and convection pattern with time.

\section{b. Near-surface moisture convergence}

As discussed in the introduction, several studies have pointed out that the frictional convergence in the boundary layer results in the eastward propagation of the ISO. Whether such a feature occurs in both the northward and eastward propagation described above is an interesting question. Shown in Fig. 4 are the lagged regression maps for moisture divergence and transport anomalies at $925 \mathrm{hPa}$. A moisture convergence anomaly prop- agates eastward from the Indian Ocean to the date line along the equator from day -15 to day 5. A careful comparison between Figs. 3 and 4 reveals that the moisture convergence anomaly tends to be located to the east of the negative OLR anomaly and appears 5 days earlier than the OLR anomaly during the eastward propagation. For example, a narrow band of moisture convergence appears in the Maritime Continent at day - 15 (Fig. 4b) while the corresponding negative OLR anomaly does not appear until day -10 (Fig. 3c). The 925-hPa moisture convergence anomaly centered at the equator, followed by a negative OLR anomaly, propagates farther eastward from the Maritime Continent to the date line between day -10 and day 5. A similar phase-lag relationship is also observed between the 10-m and 850$\mathrm{hPa}$ divergence fields (not shown), indicating a vertical 
phase shift of the divergence field toward the west. The eastward propagation of the convergence anomaly along the equator is associated with the divergence anomaly between $20^{\circ}$ and $30^{\circ} \mathrm{N}$. This north-south feature can be viewed as a regional Hadley-type circulation that propagates eastward from South Asia and the Indian Ocean to the western Pacific.

Northward propagation is again evident in the propagation routes described in the preceding paragraphs. From day -20 to day -10 , the $925-\mathrm{hPa}$ moisture convergence anomaly is collocated with the OLR anomaly. There is no obvious phase shift between the $925-\mathrm{hPa}$ moisture convergence and the OLR anomalies. The significant phase lead does not appear until day -5 , when the moisture convergence anomaly suddenly shifts to the northeast of the negative OLR anomaly.

At day -5 , when the anomalous convergence region reaches India, it becomes elongated in the northwestsoutheast direction and results in the anomalous convergence located to the north of the negative OLR anomaly in the eastern Indian Ocean. The appearance of the moisture convergence anomaly in the Bay of Bengal is associated with the eastward extension of the southwesterly anomaly from the Arabian Sea to the Bay of Bengal. The latter is in turn consistent with the enhancement and eastward extension of the cyclonic circulation, which is located to the northwest of the negative OLR anomaly, in the Arabian Sea, India, and the Bay of Bengal (Figs. 3c,d). The negative OLR anomaly in the equatorial Indian Ocean, which is nearly stationary before day -5 , with the near-surface convergence located to the north subsequently starts its northward propagation to the northern Bay of Bengal.

Similar characteristics are also observed in the South China Sea. A farther eastward extension of the southwesterly flow and the moisture convergence anomaly from the Bay of Bengal to the South China Sea occurs at day 0 . This feature is associated with the appearance of a cyclonic circulation in the South China Sea, which is located to the northwest of the negative OLR anomaly. Its similarity to Gill's solution (Gill 1980) suggests that the cyclonic circulation could be an atmospheric response to the heating in the far western equatorial $\mathrm{Pa}$ cific. The induced cyclonic anomaly in turn causes the eastward extension of the southwesterly and moisture convergence anomalies into the South China Sea. The anomalous moisture convergence, which happens to occur to the north of the negative OLR anomaly, may subsequently induce the northward propagation of the ISO in the South China Sea.

Accompanied by the anomalous convection and moisture convergence is the fluctuation of the moisture transport. During the May-August period, moisture is transported from the southern Indian Ocean into the Northern Hemisphere mostly through the Somali jet and is transported farther to South Asia, Southeast Asia, and East Asia by the prevailing southwesterly winds. The anomalous moisture transport shown in Fig. 4 reflects the fluctuation of the moisture transport due to the ISO. The southwestward moisture transport anomaly in the western Indian Ocean and the Arabian Sea at day -20 (Fig. 4a) is the reflection of a weakened southwesterly flow and moisture transport, indicating a weakened Somali jet and less moisture transport from the Southern Hemisphere to the Arabian Sea. The anomaly weakens between day -20 and day -5 and is replaced by an anomalous northeastward moisture transport at day -5 . The eastward transport expands farther to the Bay of Bengal at day 0 and to the South China Sea at day 5. The results shown above demonstrate that the expansion and contraction of the southwesterly flow and the associated moisture transport are strongly modulated by the ISO.

\section{c. Vertical structure}

The above results suggest that the mutual enhancement of convection and low-level circulation is responsible for the sequential northward propagation of the ISO and the downstream development of the ISO in subtropical Asia. Previous studies (e.g., Kemball-Cook and Wang 2001; Lawrence and Webster 2002) proposed that the frictional moisture convergence is an important process leading to the northward propagation. Under that circumstance, one should note that the moisture convergence in the boundary layer leads both its counterpart in the free lower troposphere and the deep heating. In this section, the vertical structure of the ISO is examined to shed light on this issue.

Cross sections of diabatic heating, moisture divergence, and circulation anomalies averaged between $65^{\circ}$ and $75^{\circ} \mathrm{E}$ are presented in Fig. 5 to reveal the vertical structure of the northward-propagating ISO in the Arabian Sea. At day -20 , a positive heating anomaly with maximum heating around 500-400 hPa was located near the equator. A negative heating anomaly was located to the north covering a large area from $10^{\circ}$ to $25^{\circ} \mathrm{N}$. These heating anomalies were collocated with the OLR anomalies, indicating the dominance of the latent heat release associated with deep convection. These positive and negative heating anomalies exhibited anomalous upward and downward motions, respectively. The meridional flow in between connects the ascending and descending branches to form an anomalous vertical circulation that circulates in an opposite direction to the mean reversed Hadley circulation existing in the area during the boreal summer (Webster et al. 1998). A similar vertical circulation does not exist in the Southern Hemisphere. There is also a tendency for the upward motion beneath the maximum heating to be stronger at the northern edge of the heating than at the southern edge.

During the next 10 days, the positive heating anomaly expands northward with the maximum heating shifting systematically northward. The corresponding vertical circulation to the north of the positive heating anomaly moves northward while the negative heating region dis- 
(a)lon=70E lag reg of DIVVQ,DBH,VW day $=-20$

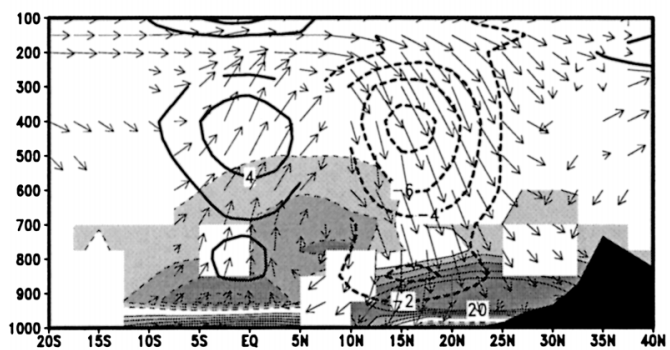

(b)lag day $=-15$

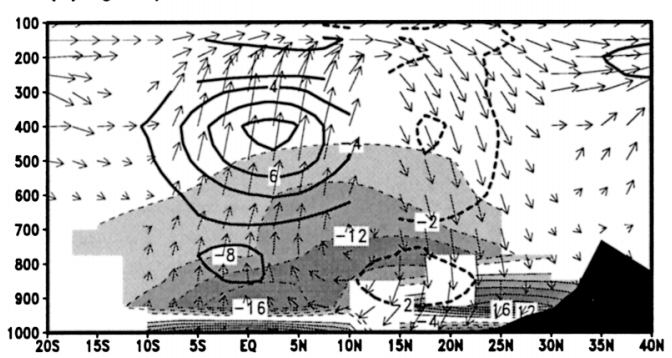

(c)lag day $=-10$

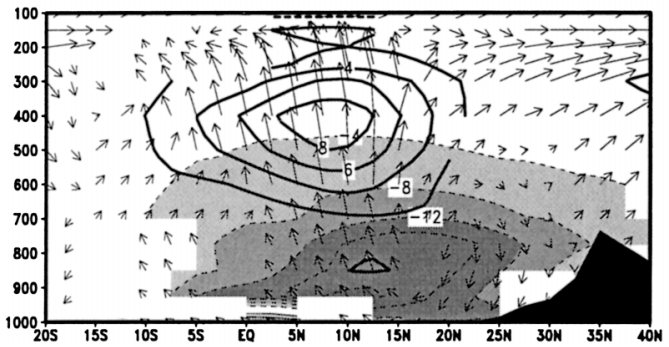

(d) lag day $=-5$

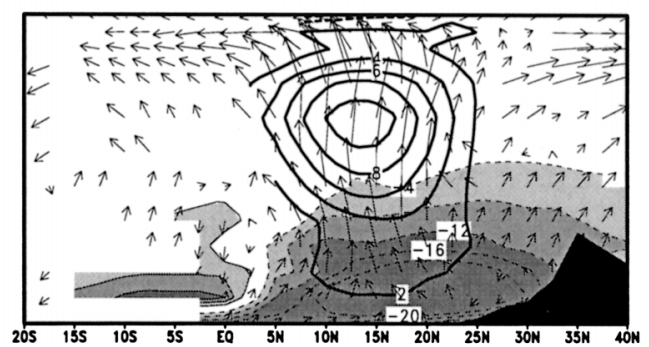

(e)lag day $=0$
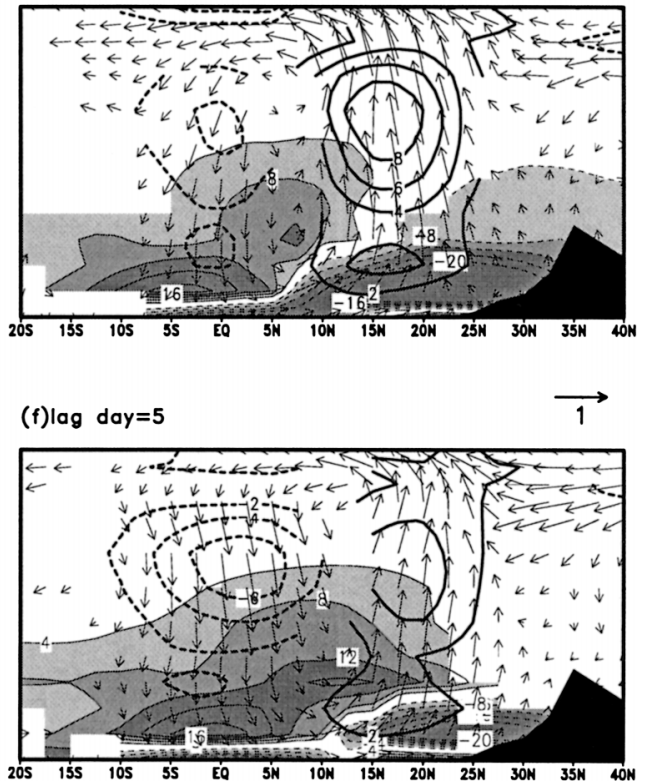

FIG. 5. Meridional cross sections of lagged regression coefficients between the expansion coefficient of the first OLR vector and the diabatic heating (contoured), meridional wind, vertical velocity, and moisture divergence (shaded) averaged from $65^{\circ}$ to $75^{\circ} \mathrm{E}$ at (a) day -20 , (b) day -15 , (c) day -10 , (d) day -5 , (e) day 0 , and (f) day 5. Contour intervals are $2 \times 10^{-6} \mathrm{~K} \mathrm{~s}^{-1}$ and $10^{-10} \mathrm{~g} \mathrm{~kg}^{-1} \mathrm{~m} \mathrm{~s}^{-2}$ for the diabatic heating and moisture divergence, respectively. Vertical velocity $(\omega)$ has been multiplied by 100 . Length of the reference arrow is equivalent to $1 \mathrm{~m} \mathrm{~s}^{-1}$ or $0.01 \mathrm{hPa} \mathrm{s}^{-1}$. Solid and dashed lines indicate positive and negative values, respectively. Regression coefficients have been multiplied by one standard deviation of the expansion coefficient and only those that are significant at the 0.05 level are plotted.

appears at day -10 . Most of the positive heating anomaly is confined in the middle troposphere before day -10 but expands to the lower troposphere by day -5 . The vertical expansion of the positive heating anomaly is consistent with the enhancement of deep convection during the northward propagation. The positive heating anomaly weakens from day 0 onward while a negative heating anomaly and a reversed vertical circulation develop in the south and move northward.

Generally speaking, near-surface moisture convergence is observed beneath the deep heating at all times. However, at days -20 and -15 , an anomalous moisture convergence region between 800 and $500 \mathrm{hPa}$ exists to the north of the deep heating in a region where no significant heating or cooling is evident. This region is well separated from the near-surface moisture convergence anomaly beneath the deep heating. The existence of this moisture convergence in the lower troposphere can certainly help in inducing the initial northward propagation. However, this feature cannot be interpreted as the frictional convergence suggested in previous studies because it is elevated above the boundary layer and is on top of a moisture divergence anomaly near the surface. Some mechanism other than the frictional effect has to be responsible for this phenomenon.

From day -10 onward, a moisture convergence anomaly extending from the surface to $500 \mathrm{hPa}$ is observed to the north of the deep heating. This convergence anomaly, piling up along the southern slope of the Tibetan Plateau, and the corresponding upward motion (e.g., Figs. 5d-5f), suggest the contribution of the lifting effect induced by the high terrain to the farther 
(a)lon=90E lag reg of DIVVQ,DBH, VW day $=-20$

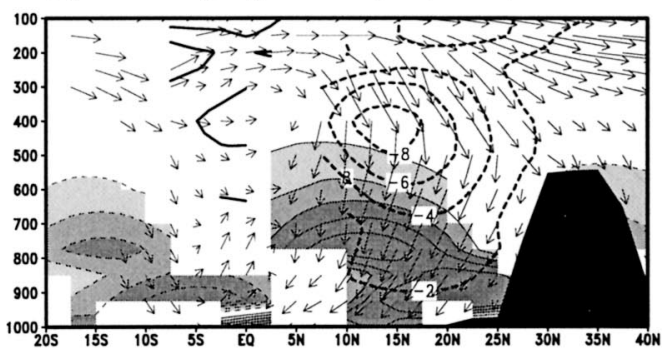

(b) lag day $=-15$

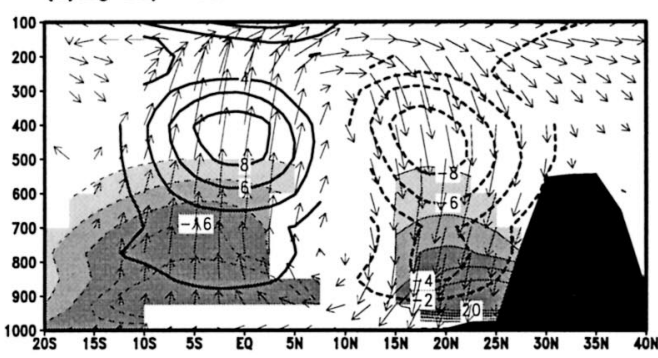

(c) lag day $=-10$

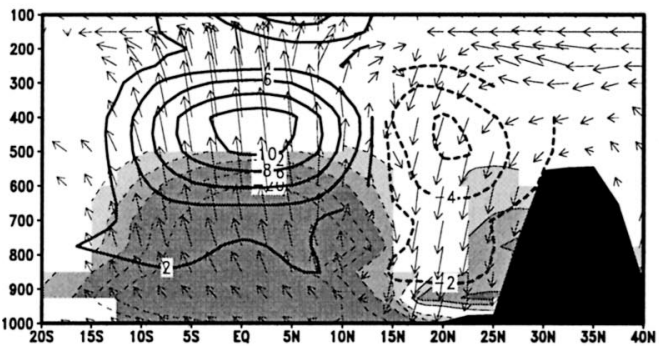

(d) lag day $=-5$

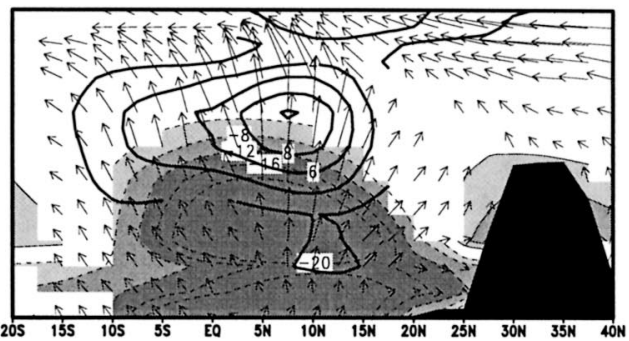

(e)lag day $=0$

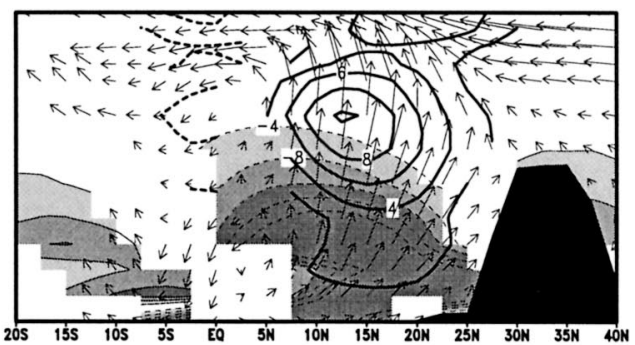

(f) lag day $=5$

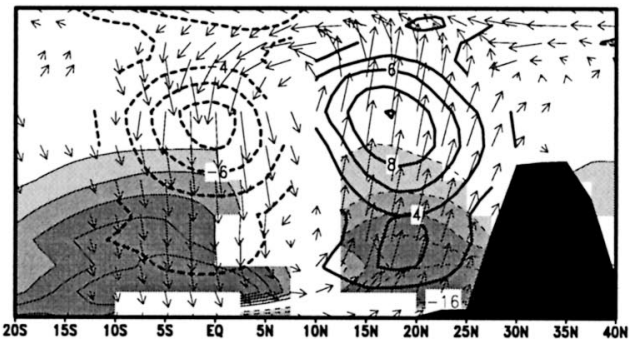

FIG. 6. Same as in Fig. 5 except for the same fields averaged from $85^{\circ}$ to $95^{\circ} \mathrm{E}$.

northward propagation of the anomaly near the landmass in South Asia. At day 0 and day 5, a moisture divergence anomaly in the lower troposphere is located near $5^{\circ} \mathrm{N}$, in a region between the deep heating and cooling anomalies. This is a situation (which is similar to its counterpart observed at day -20 and day -15 except in opposite signs) favorable for the northward propagation of the deep cooling anomaly near the equator.

Figure 6 presents the cross section averaged between $85^{\circ}$ and $95^{\circ} \mathrm{E}$ to illustrate the characteristics of the northward propagation in the eastern Indian Ocean and the Bay of Bengal. Unlike its counterpart in the Arabian Sea, the deep heating anomaly before its northward propagation (e.g., day - 15; Fig. 6a) is not accompanied by a moisture convergence anomaly in the lower troposphere located to its north. The deep moisture convergence does not appear until day -10 when the deep heating anomaly starts propagating northward. The appearance of this convergence anomaly evidently lags behind its counterpart in the Arabian Sea. This anomaly exhibits a double-peak vertical structure with a maxi- mum near the surface and another one extending from 900 to $500 \mathrm{hPa}$. The phase lag between the two convergence anomalies is not significant until day -5 when a near-surface convergence anomaly appears over the land in the southern periphery of the Tibetan Plateau and results in the southward tilting of the moisture convergence anomaly with increasing height. The deep heating anomaly subsequently continues propagating northward to $20^{\circ} \mathrm{N}$ at day 5 , and stalls and dissipates afterward. Both moisture convergence anomalies near the surface and in the lower troposphere seemingly contribute to the northward propagation. These observations are consistent with the argument presented above. That is, the eastward stretching of the southwesterly anomaly and the cyclonic anomaly from the Arabian Sea to the Bay of Bengal and the South China Sea is likely to induce the sequential northward propagation of deep convection in these oceanic regions.

The evolution of the vertical structure along the equator (averaged from $5^{\circ} \mathrm{S}$ to $5^{\circ} \mathrm{N}$ ) is shown in Fig. 7. At day -20 , deep heating anomalies occur near $60^{\circ}$ and $100^{\circ} \mathrm{E}$, corresponding to the negative OLR anomalies 
(a)EQ lag reg of DivVQ,DBH,VW day $=-20$

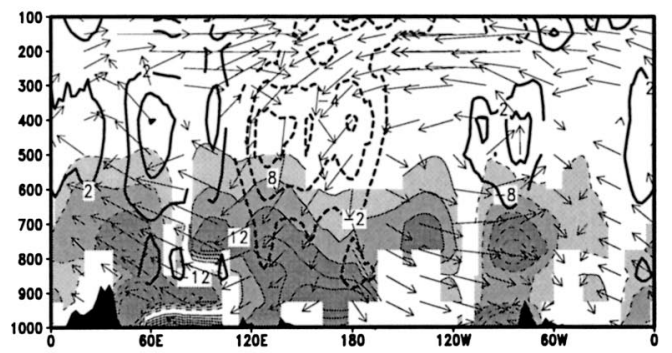

(b) log day $=-15$

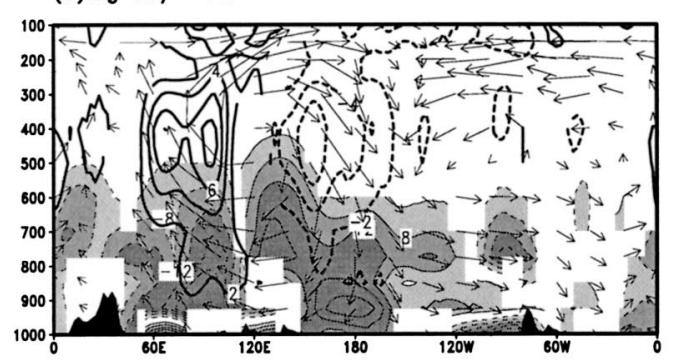

(c) lag day $=-10$

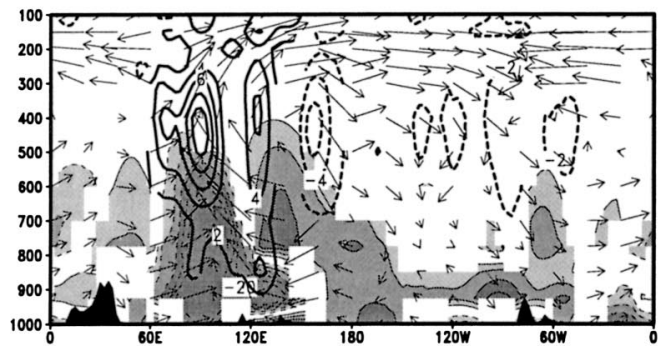

(d) lag day $=-5$

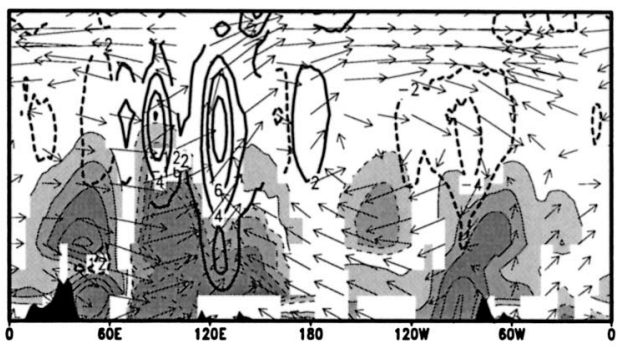

(e)lag day $=0$

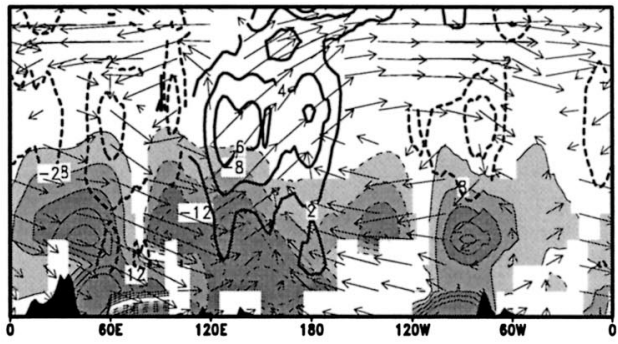

(f) log day $=5$

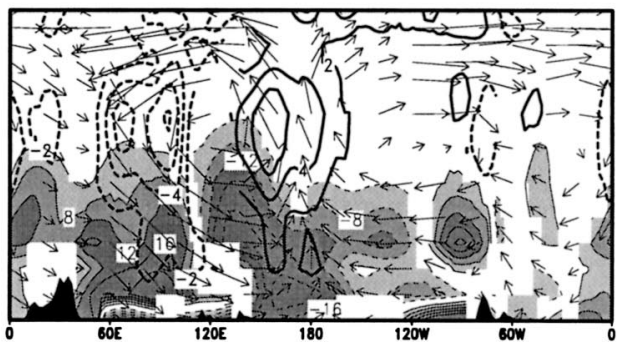

FIG. 7. Same as in Fig. 5 except for the zonal cross sections of the diabatic heating, zonal and meridional winds, and vertical velocity averaged from $5^{\circ} \mathrm{N}$ to $5^{\circ} \mathrm{S}$.

seen in Fig. 3, while a cooling anomaly occurs in a large area from $120^{\circ} \mathrm{E}$ to the date line. The heating exhibits a vertical profile with double maxima, a larger one around $500 \mathrm{hPa}$ and a smaller one near $800 \mathrm{hPa}$. The heating and cooling anomalies are accompanied by anomalous upward and downward motion, respectively. Easterly and westerly anomalies in between connect two regions of vertical motion and form a Walker-type circulation.

These two heating anomalies combine into one big heating anomaly centered near $95^{\circ} \mathrm{E}$ at day -15 , while the cooling anomaly moves eastward and centers near $150^{\circ} \mathrm{E}$. A shallow heating, located to the east of the major heating center, is again evident in the lower troposphere. The coexistence of the deep heating in the west and the shallow heating in the east is consistent with the westward tilting of the western (and ascending) branch of the Walker-type circulation with increasing height. In contrast, this westward tilting is not observed in its northward-propagating counterpart. Five days later at day -10 , a new heating anomaly with double peaks in the vertical appears near $120^{\circ} \mathrm{E}$, while the old heating anomaly remains stationary around $90^{\circ} \mathrm{E}$. Interestingly, the cooling anomaly does not continue moving eastward and begins weakening.

The heating anomaly centered near $90^{\circ} \mathrm{E}$ begins weakening at day -5 , while the one near $120^{\circ} \mathrm{E}$ strengthens and another new heating anomaly starts developing near the date line. Strong westerly and easterly anomalies in the lower troposphere appear to the west and east of the anomalous heating, respectively, and converge into the heating region in the western Pacific. An interesting feature is the sudden appearance of the Walker-type circulation with an ascending branch in the western Pacific and a descending branch in the eastern Pacific.

While the heating at $120^{\circ} \mathrm{E}$ begins weakening at day 0 , a new heating anomaly develops near $145^{\circ} \mathrm{E}$ and anomalous upward motion prevails from $120^{\circ} \mathrm{E}$ to the date line. The Walker-type circulation over the central and eastern Pacific remains stationary but contracts slightly because of the heating development near the date line. In the next 5 days, the heating near $120^{\circ} \mathrm{E}$ 
(a)lag reg of $\mathrm{T} 2 \mathrm{~m}-\mathrm{T} 700 \mathrm{hPa}$ lag day $=-20$

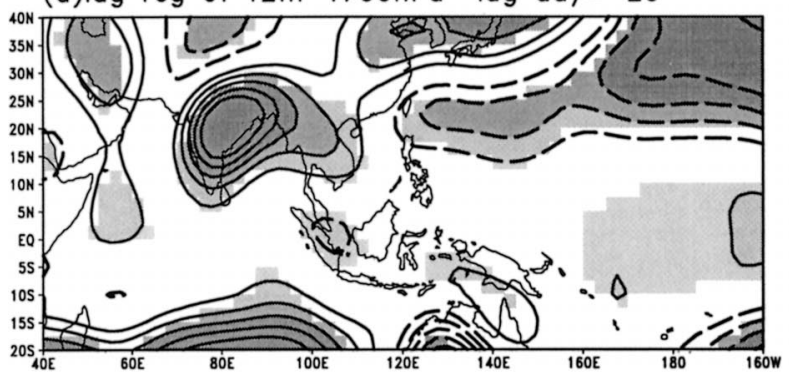

(b) lag day= $=-15$
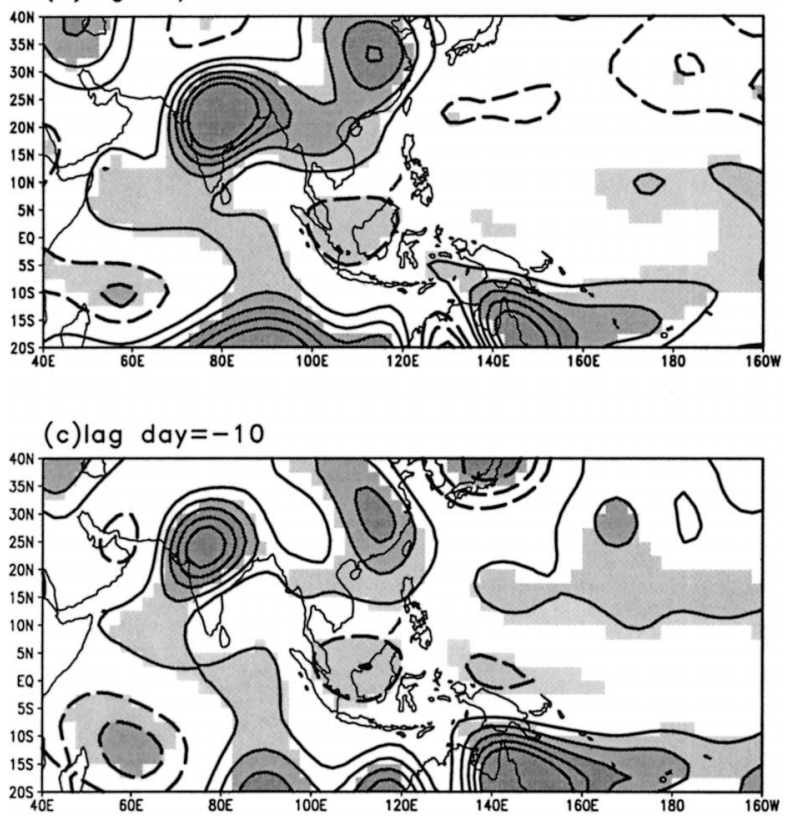

(d) lag day= $=-5$

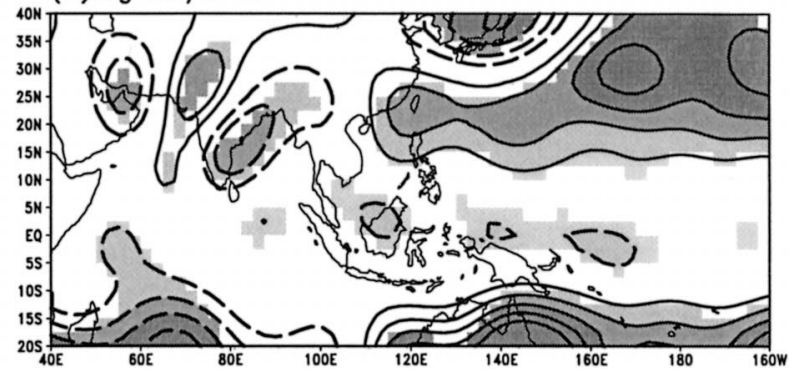

(e)lag day $=0$

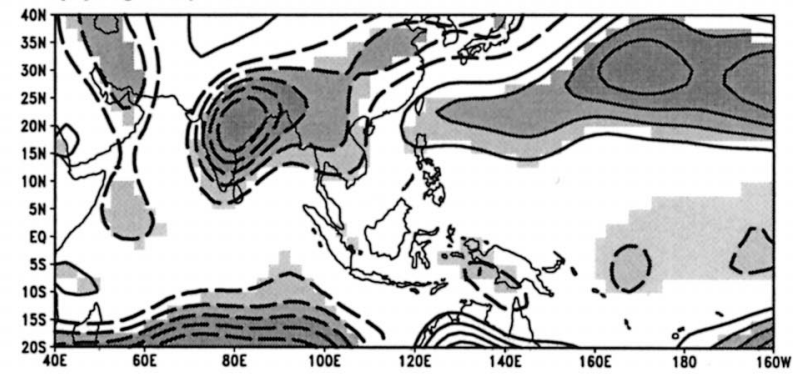

(f) lag day $=5$

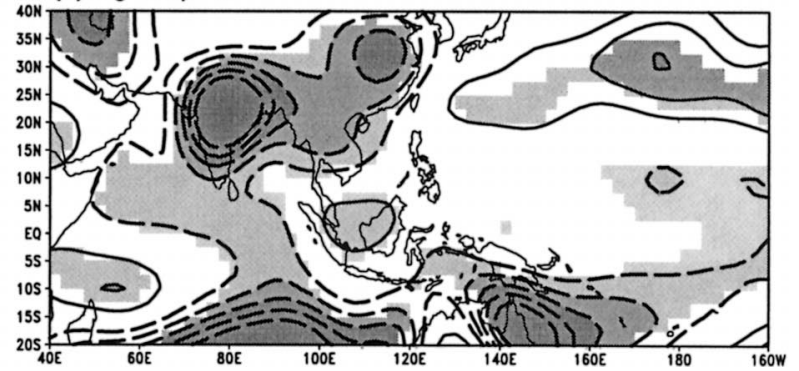

FIG. 8. Lagged regression coefficients between the expansion coefficient of the first OLR vector and the temperature difference at $2 \mathrm{~m}$ and $700 \mathrm{hPa}$ at (a) day -20 , (b) day -15 , (c) day -10 , (d) day -5 , (e) day 0 , and (f) day 5. The 2-m temperature anomalies larger than 0.06 and less than $-0.06 \mathrm{~K}$ are plotted in solid and dashed lines, respectively, and the contour interval is $0.06 \mathrm{~K}$. The regression coefficients have been multiplied by one standard deviation of the expansion coefficient. Those that are significant at the 0.05 level are highlighted by shading.

disappears while the newly developed centers to the east strengthen. By day 10, no new heating anomalies appear farther to the east and the heating anomaly from $145^{\circ} \mathrm{E}$ to the date line begins weakening (figure not shown).

Consistent with previous results, near-surface moisture convergence occurs to the east of the deep heating and is likely to induce the eastward propagation of the ISO from the Indian Ocean to the date line. The convergence also exists in the eastern Pacific but does not lead to the farther eastward propagation of the deep heating beyond the date line. This phenomenon could be attributed to the low SST and moisture content in the equatorial eastern Pacific as suggested by Salby et al. (1994).

\section{d. Surface heat fluxes}

While the northward propagation can be attributed to the low-level moisture convergence during most parts of the evolution, it is also affected by thermodynamic factors in the early stages. Figure 8 is the evolution of the difference between the 2-m height and the $700-\mathrm{hPa}$ temperature, representing the fluctuation in stability in the lower troposphere. From day -20 to day -10 , a positive difference (i.e., temperature decreasing with increasing height) can be seen in a large area from the Arabian Sea eastward to the northern South China Sea and East Asia. These positive differences exist in the subtropical region located to the north of the deep convection, which at this time is still located in the lower latitudes. Interestingly, a northeast-southwest elongated band of positive difference is found in the Arabian Sea at day -15 and day -10 . The orientation and location of this band coincide with the northeastward propagation route of the deep convection from the equatorial western Indian Ocean to northwestern India. This band appears before the occurrence of the northward propagation and disappears quickly between day -10 and 
(a) lag reg of $\mathrm{SH}$ lag day $=-20$

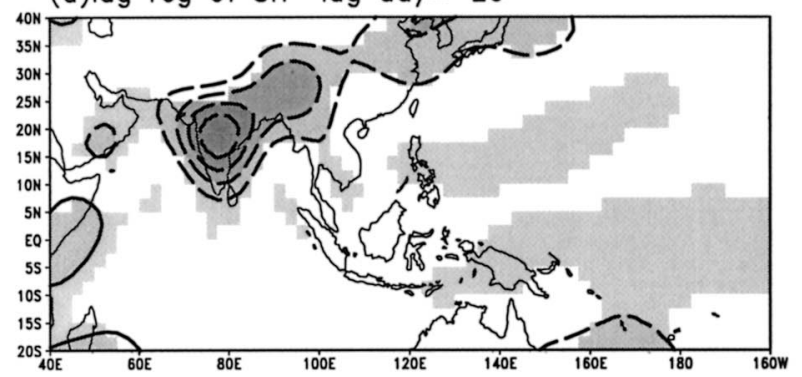

(b) lag day $=-15$

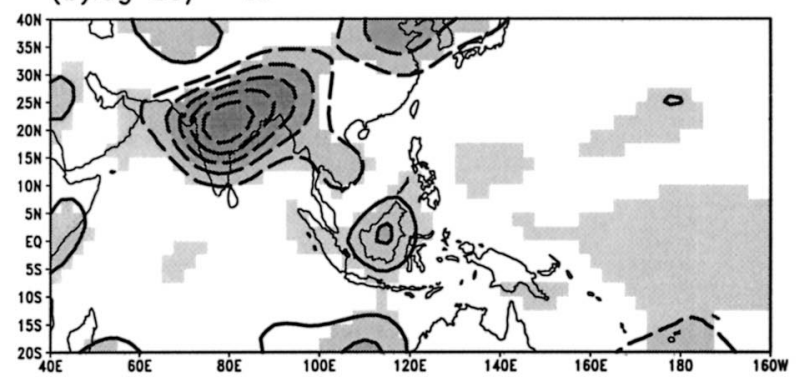

(c) lag day $=-10$

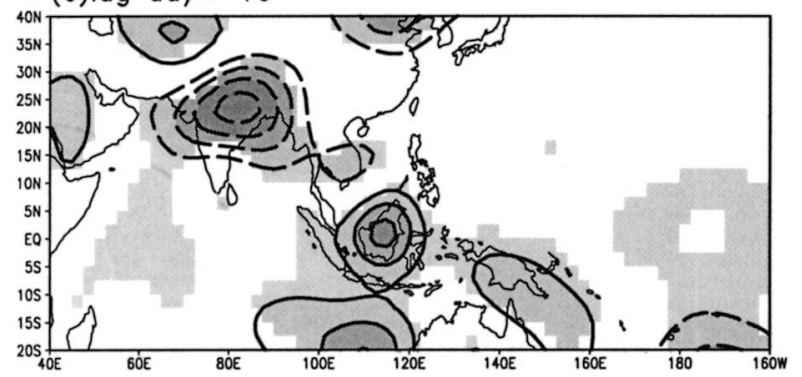

(d) lag day $=-5$

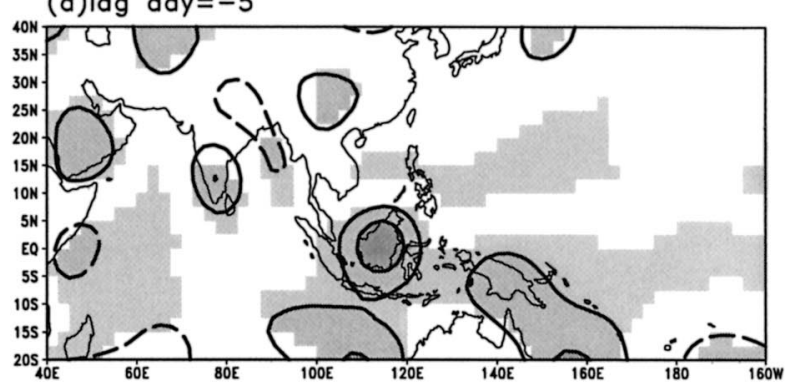

(e) $\operatorname{lag}$ day $=0$

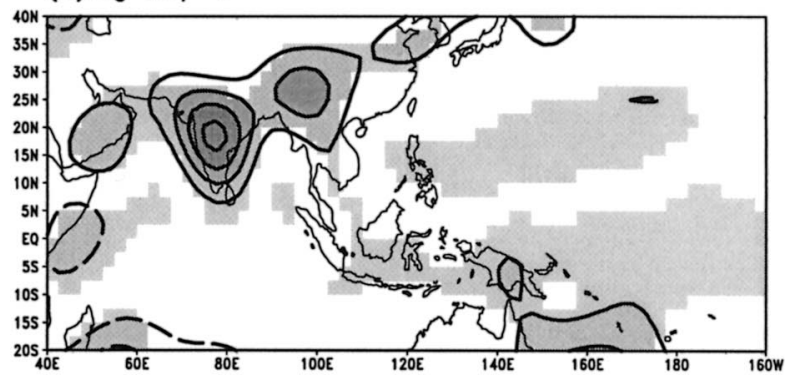

(f)lag day=5

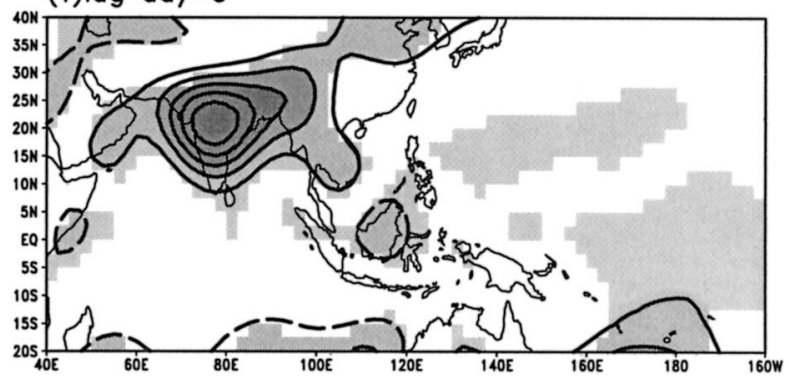

FIG. 9. Lagged regression coefficients between the expansion coefficient of the first OLR vector and the SHF anomalies at (a) day -20 , (b) day -15 , (c) day -10 , (d) day -5 , (e) day 0, and (f) day 5. Anomalies larger than 0.4 and less than $-0.4 \mathrm{~W} \mathrm{~m}^{-2}$ are plotted in solid and dashed lines, respectively. The contour interval is $0.4 \mathrm{~W} \mathrm{~m}^{-2}$. The regression coefficients have been multiplied by one standard deviation of the expansion coefficient. Those that are significant at the 0.05 level are highlighted by shading.

-5 . After the deep convection reaches the landmass of the Asian continent, the temperature difference becomes negative. The above results suggest that the existence of less stable conditions in the lower troposphere ahead of the deep convection may contribute to the northward propagation of the ISO especially in the Arabian Sea.

The vertical temperature difference fluctuation can be partly attributed to the shortwave radiation fluctuation. Our results (not shown here) indicate that the negative OLR anomaly north of $10^{\circ} \mathrm{N}$ is led by more shortwave radiation into the surface during the northward propagation. The latter appears following the positive OLR anomaly and in turn leads the positive 2-m temperature anomaly. The absorbed solar radiation must be released from the surface to the atmosphere through surface heat flux to affect the stability. Evolution of the sensible heat flux (hereafter referred to as SHF) from day -20 to day 5 is shown in Fig. 9. The negative SHF anomaly, indicating more heat flux into the atmosphere, is found to be collocated with the positive temperature-difference anomaly shown in Fig. 8. A particularly interesting feature is its northeast-southwest-oriented path, which can be seen clearly from the equatorial western Indian Ocean northeastward to northwestern India (Fig. 9c). This close spatial relationship suggests that the vertical temperature difference can be partially attributed to the transfer of sensible heat from the surface to the atmosphere during the period when the convection is not active.

Latent heat flux (hereafter referred to as LHF) from the surface to the atmosphere can also affect the stability of the lower troposphere. However, the spatial distribution of the LHF anomaly shown in Fig. 10 is very different from those shown in Figs. 8 and 9. From day -20 to day -10 , a band of positive anomaly, indicating less LHF into the atmosphere, ahead of the deep convection consistently moves northward from the equatorial Indian Ocean toward the landmass of South Asia. Comparison with Fig. 4 indicates that this positive LHF 
(a) lag reg of LH lag day $=-20$

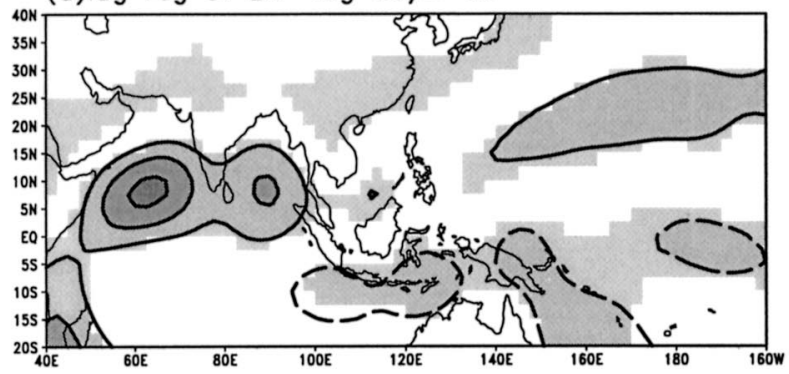

(b) lag day $=-15$

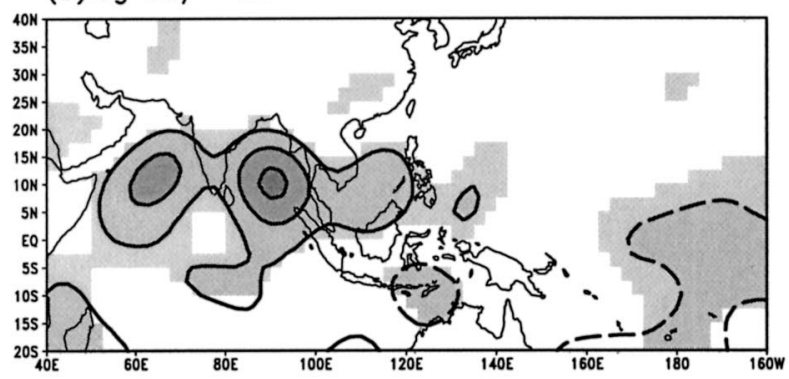

(c) lag day $=-10$

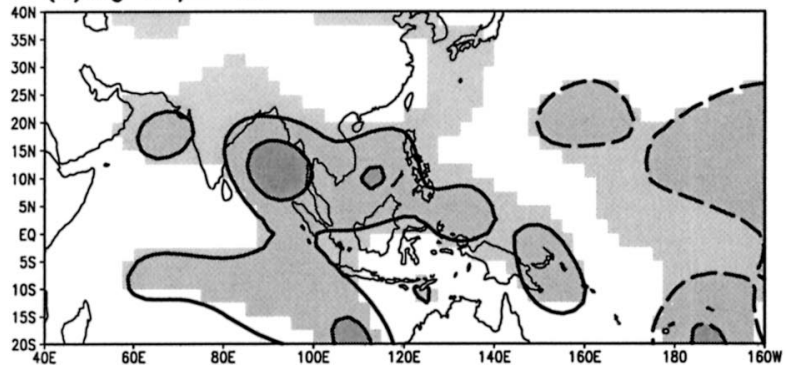

(d) lag day $=-5$

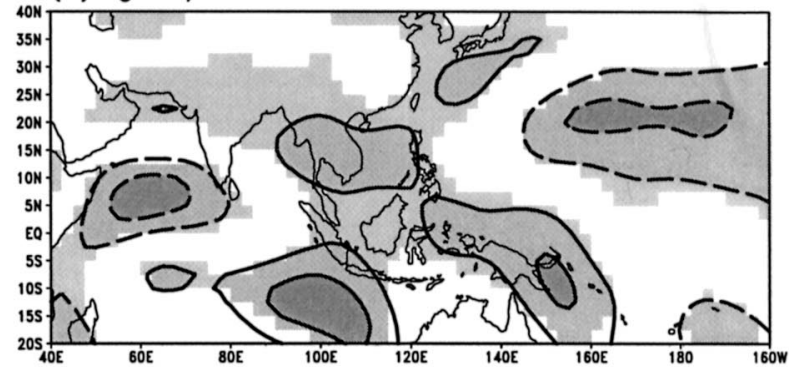

(e) lag day $=0$

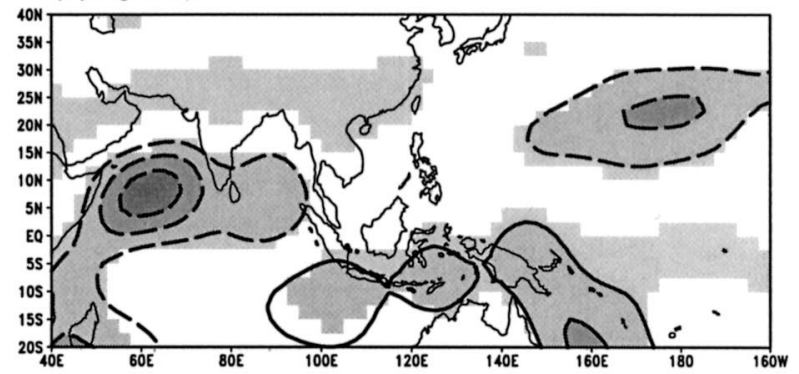

(f) lag day $=5$

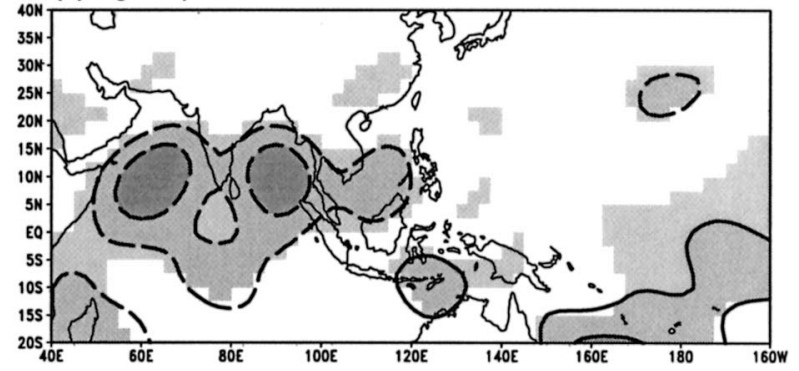

FIG. 10. Same as in Fig. 9 except for the LHF anomalies. Anomalies larger than 2 and less than $-2 \mathrm{~W} \mathrm{~m}^{-2}$ are plotted in solid and dashed lines, respectively. The contour interval is $2 \mathrm{~W} \mathrm{~m}^{-2}$.

is associated with the near-surface easterly anomaly. Climatologically, the southwesterly winds in the region extract a large amount of LHF from the ocean into the atmosphere. The existence of the prevailing near-surface easterly anomaly to the north of the deep convection is consistent with the positive LHF anomaly (i.e., less heat flux into the atmosphere). More LHF is released to the atmosphere only after the passage of the deep convection and the following enhancement of the southwesterly winds in the region (e.g., from day -5 to day 5 ). It follows that the ocean and land surface located to the north of the deep convection would not be able to provide LHF to destabilize the lower troposphere for the preconditioning of the deep convection during the northward propagation. Instead, the needed moisture is transported into the regions by circulation largely from ocean to land. This result is at odds with the proposed mechanisms of Webster (1983) and Goswami and Shukla (1984). Both of those modeling studies suggested the important contribution of surface evaporation over land, instead of ocean, to the northward propagation.
In contrast to the spatial relationship seen in the northward propagation, both the SHF and LHF anomalies are positive (i.e., less flux into the atmosphere) to the east of the eastward-propagating deep convection near the equator. The temperature difference shown in Fig. 8 also indicates the leading phase of the negative anomaly relative to the deep convection. These characteristics are consistent with the results of previous studies (e.g., Jones and Weare 1996; Zhang 1996; Hendon and Glick 1997, among others). During the eastward propagation along the equator, the underlying surface heating does not seem to create an environment suitable for the development of deep convection ahead of the deep convection. Instead, the near-surface convergence is the key element resulting in the eastward propagation.

\section{Discussion and conclusions}

This study investigates the characteristics of the evolution and structure of the eastward- and northwardpropagating ISO in the Indian Ocean and the western 
Pacific during the boreal summer. While there are similarities between the two propagating systems, contrasting characteristics are also observed. Detailed characteristics are summarized and mechanisms are proposed as follows.

\section{a. Eastward propagation}

As has been reported in previous studies, the eastward propagation of the ISO along the equator starts in the western Indian Ocean and stalls near the date line. The near-surface moisture convergence located to the east of the deep convection region appears to result in the eastward propagation of the ISO. This result is consistent with previous studies by Salby et al. (1994), Maloney and Hartmann (1998), etc. Because of the nearsurface convergence, the vertical heating profile exhibits double peaks in the middle and lower troposphere. Correspondingly, the western branch of the Walker-type circulation tilts westward with increasing height. While the deep convection stalls near the date line, the heating in the equatorial western Pacific is connected with the cooling in the equatorial eastern Pacific by a Walkertype circulation.

The eastward propagation is not as smooth of a propagation as it should be in eastward-propagating equatorial waves. Instead, it is characterized by the sequentially downstream development of deep convection (and heating) occurring mainly in certain regions such as $60^{\circ}$, $95^{\circ}, 120^{\circ}$, and $145^{\circ} \mathrm{E}$, and near the dateline. In other words, it is a combination of stationary and propagating components. Similar results have been reported in previous studies on the boreal winter ISO (e.g., Hsu et al. 1990; Hsu 1996; Weickmann and Khalsa 1990; Zhang and Hendon 1997).

\section{b. Northward propagation}

All of the northward propagation of the deep convection reported here is led by the low-level moisture convergence located to the north. Our results, which reveal this mechanism in greater detail, indicate that this moisture convergence is not confined in the boundary layer as has been suggested in previous studies (e.g., Kemball-Cook and Wang 2001; Lawrence and Webster 2002); instead it is a deep structure extending from the surface to the middle troposphere. This phenomenon is particularly evident in the Arabian Sea. Obviously, the frictional moisture convergence cannot be applied in explaining the initial propagation. The mobile waveCISK mechanism proposed by Krishnan and Venkatesan (1997) would produce features similar to the observed structure and can be considered a plausible mechanism for explaining the northward propagation in the Arabian Sea.

Near-surface convergence does appear but only after the systems approach the landmass in the north. The near-surface moisture convergence accompanied by as- cending motion tends to pile up against the sloping terrain. Our results suggest that both the deep convergence in the lower free atmosphere and in the boundary layer contribute to the northward propagation. Lawrence and Webster (2002) suggested that the frictional convergence embedded in the Rossby wave, which is induced by the heating in the south, can result in the northward propagation of the deep convection. This may seem at odds with Gill's result (Gill 1980), because the Rossby wave is located to the northwest of heating. However, Gill's result was derived based on a resting basic state. It is possible that the forced Rossby wave can be located directly to the north of the deep convection in a realistic basic states. In that case, the deep convection and circulation will propagate northward. Conversely, the deep convection could propagate northwestward like the ISO in the western North Pacific (Hsu and Weng 2001), if the Rossby wave response is located to the northwest. Further modeling studies are certainly needed to provide a correct answer. In addition to the frictional effect, the appearance of the near-surface convergence near the landmass in South Asia suggests that the lifting effect of the sloping terrain and the stronger surface frictional effect over land could also contribute toward inducing the convergence leading the deep convection. This argument is supported by the following facts: 1) the northward propagation is most evident in South Asia where the landmass and the high-rising terrain are located and 2) the near-surface moisture convergence is not observed in the initial propagation.

One interesting feature that has rarely been discussed in previous studies is the sequential occurrence (or downstream development) of the northward-propagating deep convection from west to east in the following order: the Arabian Sea, the Bay of Bengal, and the South China Sea. The following is proposed to explain this phenomenon. After the deep convection begins moving northeastward in the Arabian Sea, the southwesterly anomaly trailing behind penetrates and transports moisture farther northeastward. This process results in the moisture convergence to the north of the deep convection in the eastern Indian Ocean (e.g., at day -5) and its subsequent northward propagation to the Bay of Bengal. As a result, the convection in the Bay of Bengal strengthens and enhances the cyclonic circulation, which expands farther eastward and transports more moisture into Indochina and the South China Sea. The deep convection in the equatorial western Pacific at this stage can also enhance the cyclonic circulation. The moisture convergence subsequently appears to the north of the deep convection in the South China Sea and triggers the northward propagation in the region. The sequentially northward propagation results in the eastward extension and the increasing zonal scale of the deep convection and the accompaning circulation in South and Southeast Asia. This feature can be mistakenly treated as eastward propagation in subtropical South Asia if plotted as a Hovmöller diagram along $10^{\circ}-20^{\circ} \mathrm{N}$. 


\section{c. Effects of surface heating}

While the low-level convergence seemingly contributes to both the eastward and northward propagation of the ISO, the effects of surface heating can be either positive or negative, depending on the situation. During the early stage of the northeastward propagation from the equatorial western Indian Ocean to the northwestern Indian subcontinent, the near-surface convergence is collocated with the deep convection. As discussed previously, the near-surface convergence cannot be the cause of the observed northeastward propagation in this region. Instead, surface heating contributes positively.

A mechanism based on the observed features is proposed as follows. An inactive convection in South Asia leads to an increased net downward radiation, which in trun results in the warming of the underlying surface. During the inactive convection phase, the southwesterly flow is also weaker than normal and the underlying surface (especially the ocean) releases less LHF into the atmosphere. This effect helps maintain the positive SST and 2-m temperature anomalies. However, more SHF is transferred into the atmosphere over the warmed surfaces. As a result, the relatively dry air near the surface becomes increasingly less stable after being heated by the underlying surface for some periods and becomes more susceptible to the development of deep convection. This thermodynamic process seemingly contributes to the northward propagation of the ISO from the Indian Ocean to the land area of South Asia. This effect is particularly evident in the Arabian Sea in the early stage of the northeastward propagation.

After deep convection is established in South Asia, the Asian summer monsoon enters its active phase. The strengthened southwesterly flow encourages evaporation over the ocean surface and transports moisture into the convection region located to the north to sustain and even enhance the deep convection. The released latent heat in turn forces atmospheric circulation, which extracts more LHF from the ocean. This system can maintain itself for some time through the positive feedback between the convection and the circulation, and with the supply of abundant moisture from the ocean. Although the near-surface moisture convergence is now located to the north of the deep convection, the system has reached the southern periphery of the Tibetan Plateau and starts dissipating and does not propagate farther north, possibly due to both the friction and the decreasing moisture supply from the south.

The underlying surface heating has a distinctively different effect on the eastward propagation along the equator. To the east of the deep convection where the near-surface convergence occurs there exist weak downward SHF and LHF. The underlying surface heating is working to stabilize the lower troposphere and its thermodynamic effect is not favorable for the development of deep convection. Our preliminary investigation of the cloud distribution based on International Satellite
Cloud Climatology Project (ISCCP) data (not shown) indicates the existence of low clouds to the east of the deep convection. This result is consistent with the nearsurface convergence and shallow heating. The dynamic effect (i.e., frictional convergence) is the dominant factor leading to eastward propagation. However, both dynamic and thermodynamic effects contribute to the northward and northeastward propagation in South Asia.

In conclusion, this study proposes mechanisms to explain the northward propagation by considering both the atmosphere-surface and convection-circulation interactions. An explanation is also offered to account for the eastward convection extention and circulation in subtropical South and Southeast Asia. Different landsea contrast configurations in the zonal and meridional directions in the Indian Ocean and over South Asia have a strong effect on the ISO and result in distinctively different characteristics in the eastward and northward propagations. This effect would have a stronger impact on the ISO in the area during the boreal summer than during the winter because of the stronger surface heating. This explains why the northward propagation occurs mostly in the Asian summer monsoon region where a strong meridional heating gradient at the surface exists due to the unique land-sea contrast.

Acknowledgments. The authors thank two anonymous reviewers for their valuable and constructive comments, which led to an improvement of this paper. The study was supported by the National Science Council, Taiwan, under NSC 91-2111-M-002-014 and NSC 92-2111-M002-016-AP4.

\section{REFERENCES}

Bretherton, C. S., C. S. Smith, and J. M. Wallace, 1992: An intercomparison of methods for finding coupled patterns in climate data. J. Climate, 5, 541-560.

Chen, T.-C., R. Y. Tzeng, and M.-C. Yen, 1988: Development and life cycle of the Indian monsoon: Effect of the 30-50 day oscillation. Mon. Wea. Rev., 116, 2183-2199.

— M.-C. Yen, and S.-P. Weng, 2000: Interaction between the summer monsoons in East Asia and the South China Sea: Intraseasonal monsoon modes. J. Atmos. Sci., 57, 1373-1392.

Ferranti, L., J. M. Slingo, T. N. Palmer, and B. J. Hoskins, 1999: The effect of land-surface feedbacks on the monsoon circulation. Quart. J. Roy. Meteor. Soc., 125, 1527-1550.

Flatau, M., P. Flatau, P. Phoebus, and P. Niiller, 1997: The feedback between equatorial convection and local radiative and evaporation processes: The implications for intraseasonal oscillation. J. Atmos. Sci., 54, 2373-2386.

Gibson, J. K., P. Kallberg, S. Uppala, A. Hernandez, A. Nomura, and E. Serrano, 1997: ERA description. No. 1, ECMWF Re-analysis Project Report Series, European Centre for Medium-Range Weather Forecasts, Shinfield, Reading, United Kingdom, 72 pp.

Gill, A., 1980: Some simple solutions for heat-induced tropical circulation. Quart. J. Roy. Meteor. Soc., 106, 447-462.

Goswami, B. N., and J. Shukla, 1984: Quasi-periodic oscillation in a symmetric general circulation model. J. Atmos. Sci., 41, 2037.

Hamming, R. W., 1989: Digital Filters. Prentice Hall, 284 pp.

Hayashi, Y. Y., and A. Sumi, 1986: The 30-40 day oscillations sim- 
ulated in an "Aqua Planet" model. J. Meteor. Soc. Japan, 64, 451-467.

Hendon, H. H., 1988: A simple model of the 40-50 day oscillation. J. Atmos. Sci., 45, 569-584.

— , and M. L. Salby, 1994: The life cycle of the Madden-Julian oscillation. J. Atmos. Sci., 51, 2225-2237.

— , and J. Glick, 1997: Intraseasonal air-sea interaction in the tropical Indian and Pacific Oceans. J. Climate, 10, 647-661.

Hsu, H.-H., 1996: Global view of the intraseasonal oscillation during northern winter. J. Climate, 9, 2386-2406.

— , and C.-H. Weng, 2001: Northwestward propagation of the intraseasonal oscillation in the western North Pacific during the boreal summer: Structure and mechanism. J. Climate, 14, 38343850 .

_ B. J. Hoskins, and F.-F. Jin, 1990: The 1985/86 intraseasonal oscillation and the role of the extratropics. J. Atmos. Sci., 47, 823-839.

Jones, C., and B. C. Weare, 1996: The role of low-level moisture convergence and ocean latent heat fluxes in the Madden and Julian oscillation: An observational analysis using ISCCP data and ECMWF analyses. J. Climate, 9, 3086-3104.

Kemball-Cook, S., and B. Wang, 2001: Equatorial waves and air-sea interaction in the boreal summer intraseasonal oscillation. J. Climate, 14, 2923-2942.

Knutson, T. R., and K. M. Weickmann, 1987: 30-60 day atmospheric oscillations: Composite life cycles of convection and circulation anomalies. Mon. Wea. Rev., 115, 1407-1436.

Krishnamurti, T. N., and D. Subrahmanyam, 1982: The 30-50 day mode at $850 \mathrm{mb}$ during MONEX. J. Atmos. Sci., 39, 2088-2095.

Krishnan, R., and C. Venkatesan, 1997: Mechanisms of low frequency intraseasonal oscillation of the Indian summer monsoon. Meteor. Atmos. Phys., 62, 101-128.

Lau, K. M., and P. H. Chan, 1986: Aspects of the 40-50 day oscillation during the northern summer as inferred from outgoing longwave radiation. Mon. Wea. Rev., 114, 1354-1367.

— oscillation in the tropical atmosphere. Part I: Theory. J. Atmos. Sci., 44, 950-972.

Lawrence, D. M., and P. J. Webster, 2002: The boreal summer intraseasonal oscillation: Relationship between northward and eastward movement of convection. J. Atmos. Sci., 59, 1593-1606.

Liebmann, B., and C. A. Smith, 1996: Description of a complete (interpolated) outgoing longwave radiation dataset. Bull. Amer. Meteor. Soc., 77, 1275-1277.

Madden, R. A., and P. R. Julian, 1971: Detection of a 40-50 day oscillation in the zonal wind in the tropical Pacific. J. Atmos. Sci., 28, 702-708.

- , and — 1972: Description of global-scale circulation cells in the tropics with a 40-50 day period. J. Atmos. Sci., 29, 1109 1123.

Maloney, E. D., and D. L. Hartmann, 1998: Frictional moisture convergence in a composite life cycle of the Madden-Julian oscillation. J. Climate, 11, 2387-2403.

Murakami, T., and T. Nakazawa, 1985: Tropical 45 day oscillations during the 1979 northern summer. J. Atmos. Sci., 42, 1107-1122.

Reynolds, R. W., and T. M. Smith, 1994: Improved global sea surface temperature analyses using optimum interpolation. J. Climate, 7, 929-948.

Salby, M. L., R. R. Garcia, and H. H. Hendon, 1994: Planetary-scale circulation in the presence of climatological and wave-induced heating. J. Atmos. Sci., 51, 2344-2367.

Sardeshmukh, P. D., and B. J. Hoskins, 1984: Spatial smoothing on the sphere. Mon. Wea. Rev., 112, 2524-2529.

Seager, R., and S. E. Zebiak, 1994: Convective interaction with dynamics in a linear primitive equation model. J. Atmos. Sci., 51, 1307-1331.

Sikka, D. R., and S. Gadgil, 1980: On the maximum cloud zone and the ITCZ over Indian longitudes during the southwest monsoon. Mon. Wea. Rev., 108, 1840-1853.

Srinivasan, J., S. Gadgil, and P. J. Webster, 1993: Meridional propagation of large-scale monsoon convective zones. Meteor. Atmos. Phys., 52, 15-35.

Wallace, J. M., C. Smith, and C. S. Bretherton, 1992: Singular value decomposition of wintertime sea surface temperature and 500mb height anomalies. J. Climate, 5, 561-576.

Wang, B., and H. Rui, 1990a: Dynamics of the coupled moist KelvinRossby wave on an equatorial $\beta$-plane. J. Atmos. Sci., 47, 397413.

__ and H. Rui, 1990b: Synoptic climatology of transient tropical intraseasonal convection anomalies. Meteor. Atmos. Phys., 44, 43-61.

_- and X. Xie, 1996: Low frequency equatorial waves in vertically sheared zonal flow. Part I: Stable waves. J. Atmos. Sci., 53, 449467.

—_, and — 1997: A model for the boreal summer intraseasonal oscillation. J. Atmos. Sci., 54, 72-86.

Webster, P. J., 1983: Mechanisms of monsoon low-frequency variability: Surface hydrological effects. J. Atmos. Sci., 40, 2110_ 2124.

_ V. O. Magaña, T. N. Palmer, J. Shukla, R. A. Tomas, M. Yanai, and T. Yasunari, 1998: Monsoons: Processes, predictability, and the prospects for prediction. J. Geophys. Res., 103, 14 451-14 510 .

Weickmann, K. M., and S. J. S. Khalsa, 1990: The shift of convection from the Indian Ocean to the western Pacific Ocean during a 30-60 day oscillation. Mon. Wea. Rev., 118, 964-978.

Woolnough, S. J., J. M. Slingo, and B. J. Hoskins, 2000: The relationship between convection and sea surface temperature on intraseasonal timescales. J. Climate, 13, 2086-2104.

Wu, M. L. C., S. Schubert, and N. E. Huang, 1999: The development of the south Asian summer monsoon and the intraseasonal oscillation. J. Climate, 12, 2054-2075.

Yasunari, T., 1979: Cloudiness fluctuations associated with the Northern Hemisphere summer monsoon. J. Meteor. Soc. Japan, 57, 227-242.

- 1981: Structure of an Indian summer monsoon system with around 40-day period. J. Meteor. Soc. Japan, 59, 336-354.

Zhang, C., 1996: Atmospheric intraseasonal variability at the surface in the tropical western Pacific Ocean. J. Atmos. Sci., 53, 739758 .

_- and H. H. Hendon, 1997: Propagating and standing components of the intraseasonal oscillation in tropical convection. J. Atmos. Sci., 54, 741-752. 